\title{
Good Without God? Connecting Religiosity, Affiliation And Pro-sociality Using World Values Survey Data And Agent-based Simulation
}

\author{
Ross Gore $^{1, *}$, Luke Galen $^{2 \diamond}$, Phil Zuckerman $^{4 \ddagger}$, David Pollock $^{5 \ddagger}$, F. LeRon Shults ${ }^{3 \odot}$ \\ 1 Virginia Modeling, Analysis and Simulation Center, Old Dominion University, Suffolk, VA, USA \\ 2 Dept. of Psychology, Grand Valley State University, Allendale, MI, USA \\ 3 Dept. of Global Development and Social Planning, University of Agder, Agder, Norway \\ 4 Dept. of Sociology and Secular Studies, Pitzer College, Claremont, CA, USA \\ 5 European Humanist Federation, Brussels, Belgium
}

PThese authors contributed equally to this work.

$\ddagger$ These authors also contributed equally to this work.

* ross.gore@gmail.com

\begin{abstract}
We investigate the relationships among individuals' religiosity (or secularity), affiliation with like-minded religious others, volunteerism, and trust and tolerance. Using data analysis of the World Values Survey, we pose and answer research questions about the types of individuals who are the most trusting, the most tolerant, and who volunteer the most. We show how distinguishing between different types of volunteer activities and using longitudinal data can provide more insight into these questions. We also use an established agent-based model to generate measures similar to those operationalized in the World Values Survey. We then reproduce the findings of the World Values Survey data analysis and extract the internal dynamics of simulation experiments (under a reasonable parameterization of the model) to provide an explanation for those findings.
\end{abstract}

\section{Author summary}

Understanding the role that religiosity (or secularity) plays in an individual's life requires clarification of the relationship between his or her beliefs and social behaviors. This complex problem can be rendered more tractable by initially fractionating "religion" into (1) belief in God and (2) affiliation with like-minded individuals in a religious organization (e.g., church, temple, or mosque). Further, we subdivide altruistic social behavior into volunteerism, trust of others and tolerance of others. With these distinctions in place, we analyze data across different time periods and countries to find the link between individual religiosity and social behavior. We find that individuals who believe in God and affiliate with a church are more likely to volunteer for altruistic activities within and outside the church. However, such individuals are also less likely to be trusting and tolerant of others. We used an agent-based model to identify the causes of these connections in the data analysis results. The simulation experiments reproduced the results observed in the data analysis, showing that affiliation provides individuals with a social network that generates additional volunteering opportunities inside and outside of the church. However, such religious networks are more likely to include individuals who are not tolerant of others and this lack of tolerance can spread within the network. Exposure to intolerant church network members generally leads affiliated believers to trust fewer people and to be less tolerant of others.

\section{Introduction}

Many studies have explored the relationship between an individual's religiosity (or secularity) and his or her pro-sociality [1 5]. To our knowledge, however, no studies have distinguished between and examined the interactions among all of the following factors: belief or nonbelief in God, affiliation with a supernatural worldview club consisting of 
like minded believers (e.g., church), active pro-social voluntary actions with different beneficiaries (inside or outside the group), and passive pro-social behaviors (measured by trust and tolerance). Here we employ analysis of data from the World Values Survey (WVS) to find statistical associations between an individual's religiosity and his or her pro-sociality. We then use an agent-based model to produce an explanation of the causes of these statistical associations.

First, we operationalize the following variables in both the WVS data and in an established agent based model: (1) natural and supernatural worldviews, (2) membership in supernatural worldview clubs, (3) active pro-sociality and (4) passive pro-sociality. Although "religiosity" is a complex and contested phenomenon, empirical findings and theoretical developments in a variety of disciplines suggest that it can be usefully fractionated (at least initially) into beliefs about supernatural agents and behaviors associated with groups that accept supernatural authorities 6 9. The rationale for our fractionation of "pro-sociality" is explained below. We analyze multiple waves of the WVS and show that (1) individuals affiliated with supernatural worldview clubs are actively pro-social at a higher rate than unaffiliated individuals, (2) individuals with a supernatural worldview are actively pro-social at a higher rate than individuals with a natural worldview, but (3) when considering pro-social actions not taken on behalf of a supernatural worldview club, individuals with a natural worldview are actively pro-social at the same rate as individuals with a supernatural worldview, and (4) individuals with a natural worldview are passively pro-social (i.e. more tolerant and trusting) at a higher rate than individuals with a supernatural worldview, especially when the latter are affiliated with a supernatural worldview club.

We then use longitudinal data from the WVS to gain even more insight into how religiosity is connected to pro-sociality. Our longitudinal data analysis results show that that individuals who change their worldview or affiliation status with a supernatural worldview club exhibit different passive pro-sociality profiles prior to their change. Specifically, we show (1) that individuals who move from a supernatural worldview to a natural worldview exhibit tolerance of others at a higher rate prior to their worldview change than those individuals who move from a natural worldview to a supernatural worldview, and (2) that individuals with a supernatural worldview who shift from affiliation with a supernatural worldview club to unaffiliation with a supernatural worldview club exhibit trust of others at a higher rate than those individuals with a supernatural worldview who shift from unaffiliation with a supernatural worldview club to affiliation with a supernatural worldview club.

We also use an agent-based simulation to produce an explanation of the causes of the statistical association we identified in the WVS related to religiosity and pro-sociality. We use an established agent-based simulation of religiosity and pro-sociality to reproduce these results from our data analysis $[10$. We then extract the dynamics within the simulation to explain what causes the statistical associations uncovered in the WVS data to occur [1]. In this way the simulation serves as an explanation generation mechanism for the WVS data [12]. Finally, we discuss threats to validity and other limitations of, as well as future directions for, our work.

\section{Methods}

\section{Data Analysis}

We analyze the longitudinal data and data from two waves (Wave 2; 1990-1994 and Wave 4: 1999-2004) of the WVS 13, 14. The longitudinal data reflects data from all participants who were surveyed multiple times and provided a response to each of the measures described below except for those measures related to active pro-sociality. Survey questions related to active pro-sociality (i.e. volunteerism) were not included in the WVS longitudinal data and as a result they are not included in our longitudinal data analysis [13]. The longitudinal data analysis includes 10,088 individuals from 31 different countries. The data we use from participants in two waves of the WVS reflects individuals who were only surveyed a single time related to all the measures described below. This data covers responses from 15,784 individuals in 10 different countries $[14$.

\section{Simulation}

We use an established agent-based simulation, The Artificial Society Analytics Platform (ASAP), to create an artificial society where agents have worldviews, can be affiliated with worldview clubs, have attributes reflecting trust and tolerance and can perform pro-social actions [10]. ASAP is a model mimicking the conditions and mechanisms leading to structural, social, and cultural interactions between majorities and minorities in western societies. In it, agents grow up and then move into the work force. They die with a certain probability or if they reach their maximum life span. They 
may marry after reaching a minimum age but, to do so, they must satisfy age, extraversion, outgroup suspicion and worldview compatibility conditions related to potential partners. Once married, agents may have children and newly born agents initially inherit the extraversion, outgroup suspicion and worldview levels of their parents [10].

Within the simulation, agents have a worldview, an outgroup suspicion value and an extraversion value. Each of these is a numeric value between 0 and 1 . An agent with a worldview value above 0.5 has a supernatural worldview (i.e. believes in God) and an agent with a worldview below 0.5 has a natural worldview (i.e. does not believe in God). Agents are given an initial worldview value that can change over time based on their interactions with other agents.

Also, within the simulation, agents are designated as belonging to a majority or a minority group. The outgroup suspicion value of an agent reflects the likelihood that an interaction with an agent from the other group (i.e. majority/ minority or minority/ majority) will be negative. Finally, the extraversion value of an agent indicates how likely it is that the agent will become involved with a cause when asked by others.

Each week agents interact with their different social networks. These social networks include: (1) agent's family, (2) the agent's online social network, (3) the agent's offline social network, (4) the agent's neighbors (neighborhood), (5) the agent's co-workers (job), if the agent has a job and (6) the other members affiliated with the same supernatural worldview club, if the agent is affiliated with a supernatural worldview club. To interact agents must be at least 12 years old. Family networks consist of father and mother; neighborhood networks are all agents in same neighborhood as the given agent; online networks are agents selected at random from the entire population upon agent inception; work networks are all agents working at the same job location. Offline social networks are stochastic with the probability of being someone else's alter agent inversely proportional to the spatial distance between the given agent and the alter.

In the remainder of this section we describe how we operationalize within the context of the WVS data and the agent-based simulation: (1) natural and supernatural worldviews, (2) membership in supernatural worldview clubs, (3) active pro-sociality and (4) passive pro-sociality. Then, in the Results section we present our findings related to the data analysis and the agent-based simulation.

\section{Measure of Worldview}

\section{World Values Survey Dataset}

The worldview of an individual in our analysis can be either: (1) natural or (2) supernatural. Within the context of the World Values Survey, we determine the worldview of individual based on the following questions: (1) Do you believe in God?, (2) Do you believe in heaven?, and (3) Do you believe in hell?

If an individual answers Yes to any of those three questions their worldview is supernatural. If the individual answers No to all three of those questions then their worldview is natural. Any individual who does not fit the criteria (i.e. responded Don't know to a question(s) in such a way that neither definition applied) is excluded from the analysis.

\section{Simulation}

Recall within the agent-based simulation, each week agents interact with their different social networks. These interactions result in reinforcing and conflicting outcomes related to the agent's worldview. In every interaction with an alter agent in their social network, the agent observes an action performed by the alter agent which can be measured to determine how consistent the action is with the alter agent's worldview. This measurement occurs by the alter agent drawing a random number between -1 and 1 . A negative value reflects an action from the alter agent that is inconsistent with the alter agent's worldview. A positive value reflects an action that is consistent with the alter agent's worldview.

If the agent observes an inconsistent action from the alter agent and the agent's worldview is the same as the alter agent's then the agent is conflicted. As a result the agent's worldview is moved in the opposite direction from their worldview by a specified amount multiplied by the magnitude of the inconsistent action. If the agent observes an inconsistent action and the agent's worldview is the opposite of the alter agent's then the agent's worldview is reinforced. As a result the agent's worldview is moved towards their worldview by a specified amount multiplied by the magnitude of the inconsistent action.

Similarly, if the agent observes a consistent action and the agent's worldview is the same as the alter agent's then the agent's worldview is reinforced. As a result the agent's worldview is moved towards their worldview by a specified amount multiplied by the magnitude of the inconsistent action. On the other hand, if the agent observes a consistent action and 
their worldview is the opposite of the alter agent's then the agent's worldview is moved in the opposite direction from their worldview by a specified amount multiplied by the magnitude of the inconsistent action.

This process by which an agent updates their worldview based on their social network interactions with alter agents is shown in Figure1.

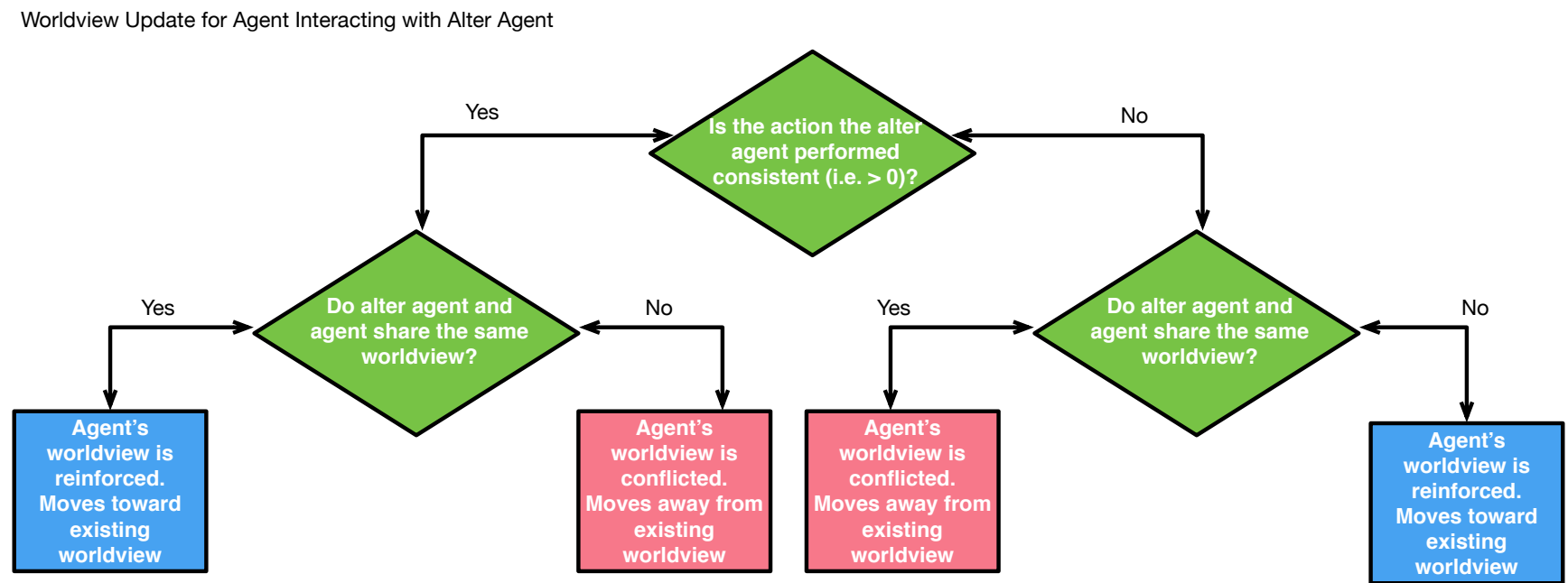

Fig 1. The process an agent goes through to update their worldview after interacting with an alter agent.

\section{Measure of Active Pro-sociality}

\section{World Values Survey Dataset}

Within the context of the World Values Survey, we measure active pro-sociality as self-reported voluntary acts associated with one of the types of organizations listed in Table 1. For each type of organization we determine if the act of pro-sociality is: (1) tribal, (2) ideological or (3) universal. Tribal pro-social actions are performed directly for the supernatural worldview club to which an individual is affiliated. Ideological pro-social actions are performed without direct consideration for an individual's worldview but taken on behalf of the individual to help themselves and others like them. Universal pro-social actions are performed without direct consideration for one's worldview or one's self. This division is based on a review of related work on understanding how and where individuals are asked and choose to volunteer $15[30]$.

Table 1. Operationalization of different types of pro-social actions.

\begin{tabular}{|c|c|c|c|}
\hline Action Type & \multicolumn{3}{|c|}{ Organization (Org.) associated with the voluntary action } \\
\hline Tribal & Church & & \\
\hline Ideological & $\begin{array}{l}\text { Labor Union } \\
\text { Professional Org. }\end{array}$ & Political Org. & Local Community Org. \\
\hline Universal & $\begin{array}{l}\text { Social Welfare Org. } \\
\text { Youth Work Org. } \\
\text { Sports/Recreation Org. }\end{array}$ & $\begin{array}{l}\text { Arts/Music Org. } \\
\text { Women's Group } \\
\text { Peace Movement Org. }\end{array}$ & $\begin{array}{l}3^{\text {rd }} \text { World Human Rights Org. } \\
\text { Conservation, Environment or Animal Org. } \\
\text { Health Org. }\end{array}$ \\
\hline
\end{tabular}

\section{Simulation}

Within the simulation, agents take pro-social actions based on a two-step process. First, for an agent the different types of pro-social action opportunities shown in Table 1 are generated based on their inclusion in different social networks. 
Specifically, for an agent to be given a tribal pro-social action opportunity the agent must be in a supernatural worldview club and a random number drawn by the agent must be above a specified threshold. For ideological and universal pro-social actions the simulation generates opportunities based on the agent's involvement in all their social networks. This includes: (1) if the agent has a job, (2) if the agent is in a supernatural worldview club, (3) if the agent is married, (4) the relative size of the agent's offline social network and (5) the relative size of the agent's online social network. In each of these cases a stochastic process is used to determine if an ideological or universal pro-social action opportunity is generated for the agent. However, the likelihood that opportunity is generated for the agent is increased based on how many different social networks the agent has and how big the agent's online and offline social networks are. This process is shown in Figure 2 ,
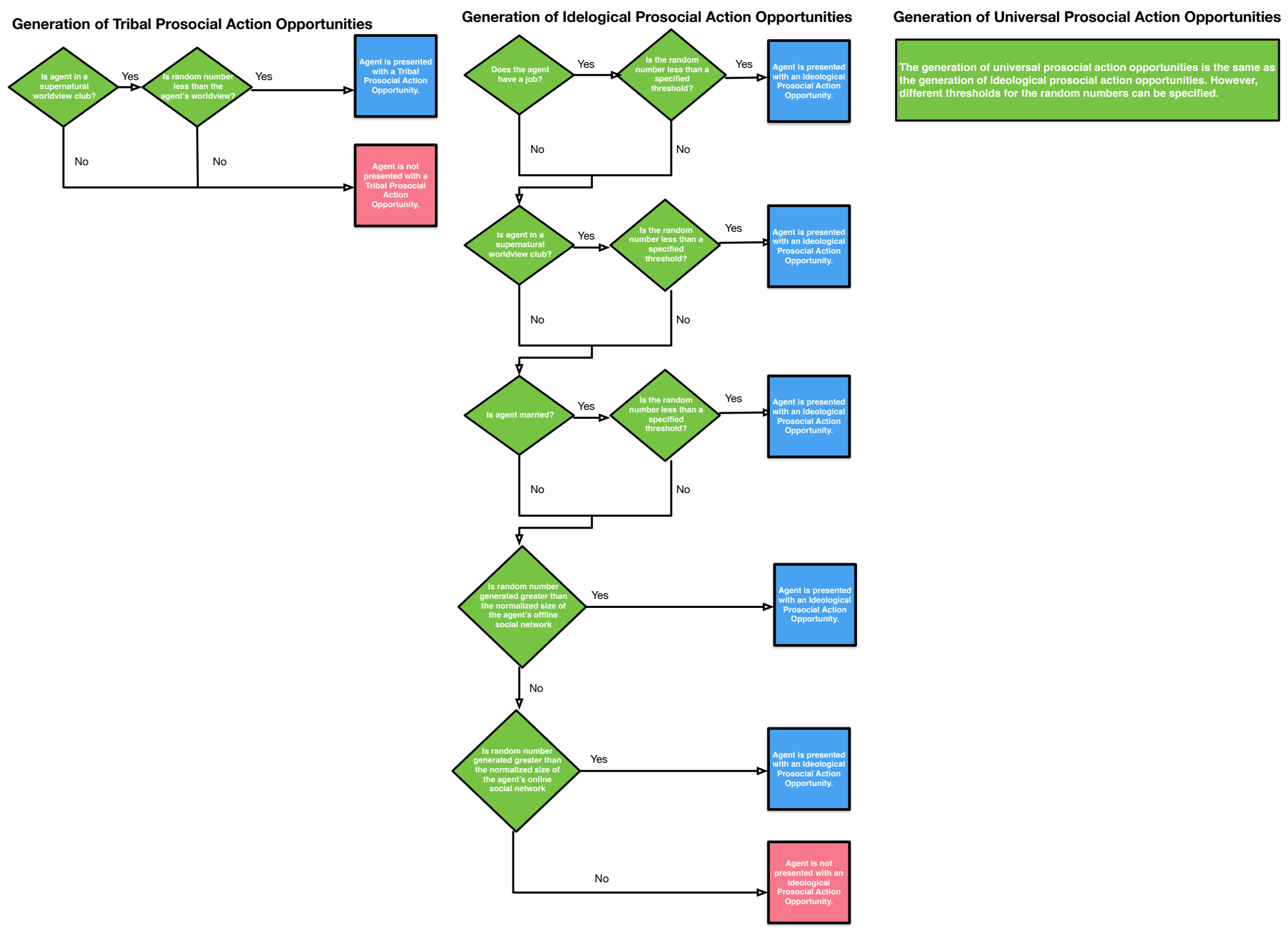

Fig 2. The process by which each type of pro-social action opportunity is generated for the agent.

It is necessary, but not sufficient, for a pro-social action opportunity of a certain type to be generated for an agent to take the pro-social action. In order to take a pro-social action an agent must accept the opportunity. An agent accepts a pro-social action opportunity based on: (1) their level of extraversion and (2) whether the agent accepted the previous opportunity. This process is shown for each of the types of pro-social action opportunities in Figure 3

The figure shows that if a random number is below the agent's extraversion level, then the agent will accept the 

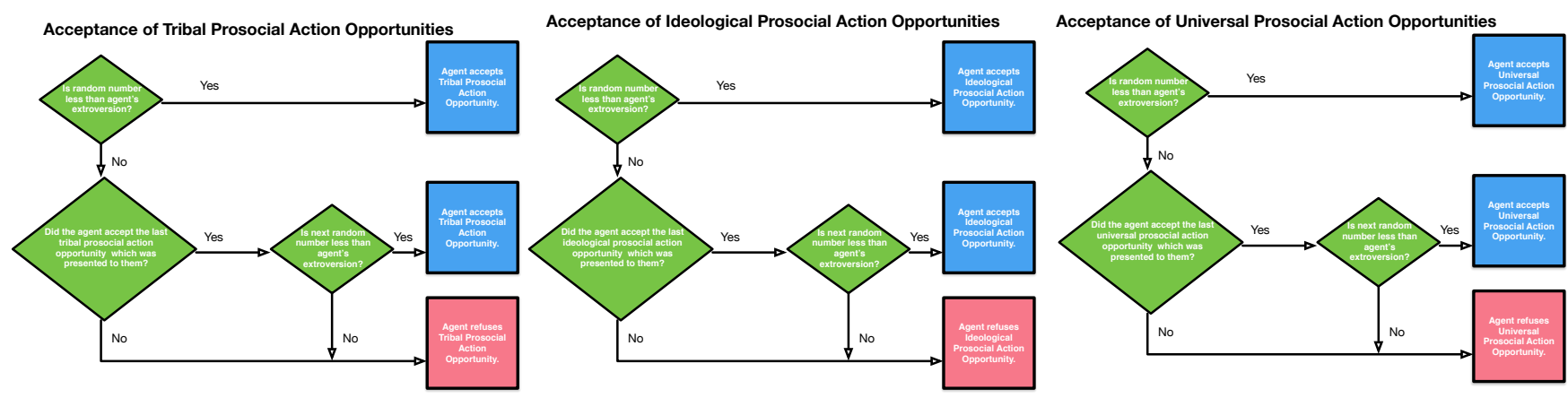

Fig 3. The process by which an agent chooses to accept or refuse each type of pro-social action opportunity presented to them.

opportunity. However, if the random number is above the agent's extraversion level and the agent had accepted an opportunity of this type the last time the agent was presented with it, then the agent will draw another random number and check if that number is below the agent's extraversion level. This dynamic doubles the likelihood the agent will accept a pro-social action opportunity if the agent had accepted the opportunity the last time it was presented to them.

\section{Measure of Passive Pro-sociality}

\section{World Values Survey Dataset}

Within the context of the World Values Survey, we measure passive pro-sociality as self-reported trust and tolerance of others. We measure the trust dimension of passive pro-sociality based on an individual's response to the question: Generally speaking, would you say that most people can be trusted or that you need to be very careful in dealing with people? An individual who responds, Most people can be trusted, exhibits the trust dimension of passive pro-sociality, while an individual who responds, Can't be too careful, does not. We measure the tolerance dimension of passive pro-sociality based on an individual's response to the question: Would you prefer to not have these people as neighbors: (1) people of a different race and (2) immigrants/foreign workers? An individual who responds, No, exhibits the tolerance dimension of passive pro-sociality, while an individual who responds, Yes, does not.

These measures are chosen based on a review of related work on how individuals can be pro-social without action. This research includes: 31 35].

\section{Simulation}

Within the agent-based simulation, passive pro-sociality also reflects measures of trust and tolerance. The trust dimension reflects a normalized measure of the total size of all of an agent's social networks. The total size of all of an agent's social networks is normalized onto a [0-1] scale by determining the quantile of the total size of all agent's social networks given the maximum total size of any agent's social networks. For example, an agent with a total size of all their social networks that is greater than $90 \%$ of all the other agents' total size of their social networks would have a trust level of 0.9. Similarly, an agent whose total size of all their social networks was the median value of all agents' total size of all their social networks would have a trust level of 0.5 .

The tolerance dimension in the agent-based simulation reflects 1 - outgroup suspicion value of an agent. Recall, each agent within the simulation is distinguished as belonging to either a majority or a minority group. If an agent is in the majority group, outgroup suspicion reflects the degree of suspicion the agent has towards the minority group. If the agent is in the minority group, outgroup suspicion reflects the degree of suspicion the agent has towards the majority group. Outgroup suspicion reflects the likelihood that an agent will have a negative interaction with the other group. It is measured on a $[0,1]$ scale where 0 reflects no suspicion and 1 reflects suspicion of all members of the outgroup. Thus a tolerance value of 1 reflects an agent with no suspicion and a tolerance value of 0 reflects an agent suspicious of all outgroup members. 
Recall, each week agents interact with their different social networks. These interactions can be categorized as positive, negative, or neutral and they can increase or decrease the agent's outgroup suspicion. Majority-majority and minority-minority interactions are categorized as neutral. In these interactions the difference between the alter agent's and the agent's outgroup suspicion is calculated. If the difference is positive (i.e alter agent has more outgroup suspicion than the agent) the agent's outgroup suspicion is increased by a specified amount multiplied by the magnitude of the difference. If the difference is negative (i.e alter agent has less outgroup suspicion than the agent) the agent's outgroup suspicion is decreased by a specified amount multiplied by the magnitude of the difference.

In majority-minority and minority-majority interactions the agent draws a random number between [0,1]. If the random number is above the agent's outgroup suspicion value then the agent has a positive interaction and reduces their outgroup suspicion a specified amount. If the random number is equal or below the agent's outgroup suspicion value then the agent has a negative interaction and their outgroup suspicion is increased a specified amount. These dynamics are shown in Figure 4 .

In the simulation an agent can remove an alter agent from its online or offline social network. After each new round of interactions with its social networks an agent reviews its online and offline social network. For each alter agent in the online or offline social network the agent checks if $m$ of the last $n$ interactions were neutral or positive. If this condition is true the agent retains the alter agent in its social network. However, if this is not true the agent removes the alter agent from its social network. These dynamics are shown in Figure 5 .

For the other social networks an agent may have (i.e. Family, Job, Supernatural Worldview Club, Neighborhood) agents may be added or removed. However, the addition or removal of an alter agent from these social networks in not in the control of the agent; instead the factors that govern these dynamics include if the alter agent: becomes unemployed, dies, unaffiliates from the Supernatural Worldview Club, or moves from the neighborhood.

\section{Measure of Affiliation with a Supernatural Worldview Club}

\section{World Values Survey Dataset}

Within the context of the World Values Survey, affiliation with a supernatural worldview club is determined based on an individual's answers to the question: Apart from weddings, funerals and christenings, about how often do you attend religious services? If an individual with a supernatural worldview responds more than once a week, once a week or once a month to the question then $\mathrm{s} /$ he is affiliated with a supernatural worldview club. It is important to note that we do not attempt to identify individuals who are affiliated with a natural worldview club. This is due to a lack of suitable questions included in the WVS to identify these individuals.

\section{Simulation}

Agents in our simulation with a supernatural worldview can be affiliated with a supernatural worldview club. A supernatural worldview club has a designated leader, called an exemplar. In order to affiliate with a supernatural worldview club an agent must: (1) have a supernatural worldview, (2) not be in another supernatural worldview club, (3) be connected to the club's exemplar agent in one of their social networks, (4) have had their last interaction with the exemplar agent be positive or neutral, and either (5a) have last observed the exemplar agent act in a manner consistent with a supernatural worldview or (5b) have an outgroup suspicion value above a specified threshold.

An agent may choose to leave the supernatural worldview club if any of the following are true: (1) the worldview of the agent is no longer supernatural, (2) $m$ of the last $n$ interactions with the exemplar agent have not been positive or neutral, or (3) the agent has not observed the exemplar agent act in a manner consistent with the exemplar's worldview in $m$ of the last $n$ interactions, and the agent's outgroup suspicion is below the specified threshold.

The decision to include outgroup suspicion as a factor for affiliation stems from the theories of identity fusion and terror management [36, 37]. Identity fusion theory demonstrates that individuals who are strongly fused to their groups, or devoted actors, are more antagonistic to outgroups 38, 39 while terror management suggests that perceiving any threat, especially outgroup threats, drives people to seek consolation and comfort in rituals with ingroup 40, 41.

These processes by which an agent affiliates or unaffiliates with a supernatural worldview club are shown in Figure 6 . 
Outgroup Update for Agent Interacting with Alter Agent

Majority (Agent) - Minority (Alter Agent) or Minority (Agent) - Majority (Alter Agent)

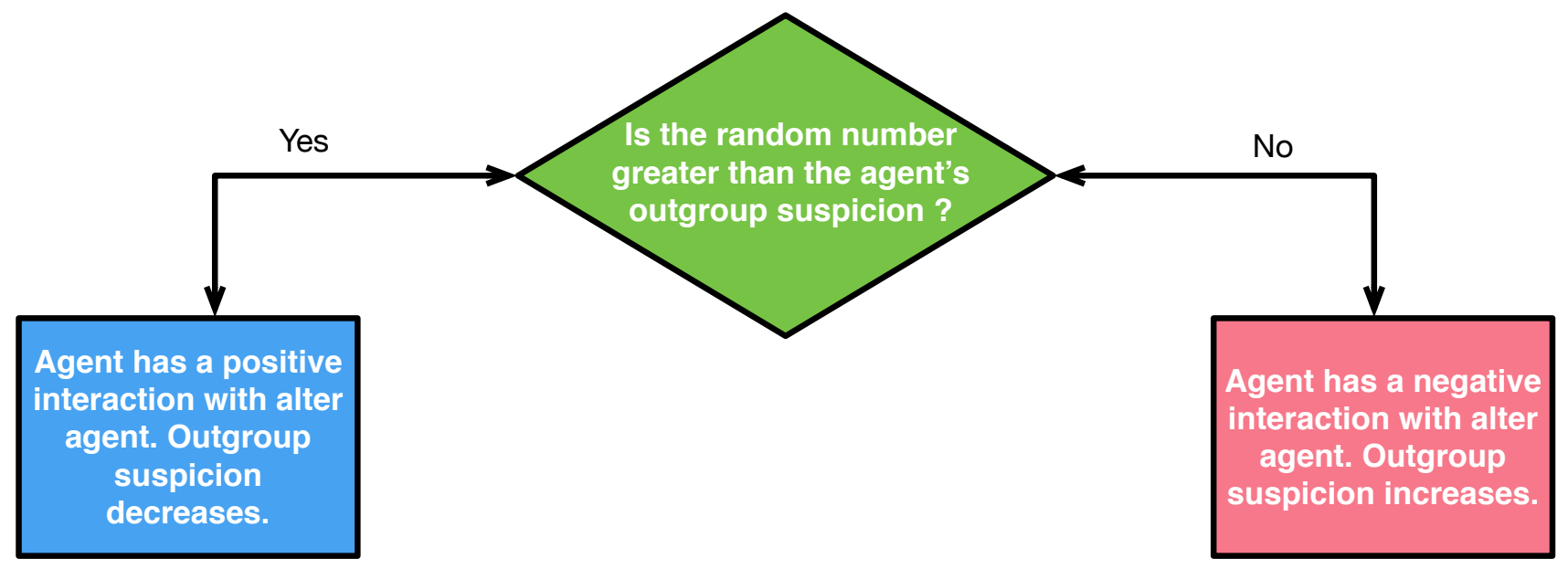

Outgroup Update for Agent Interacting with Alter Agent

Majority (Agent) - Majority (Alter Agent) or Minority (Agent) - Minority (Alter Agent)

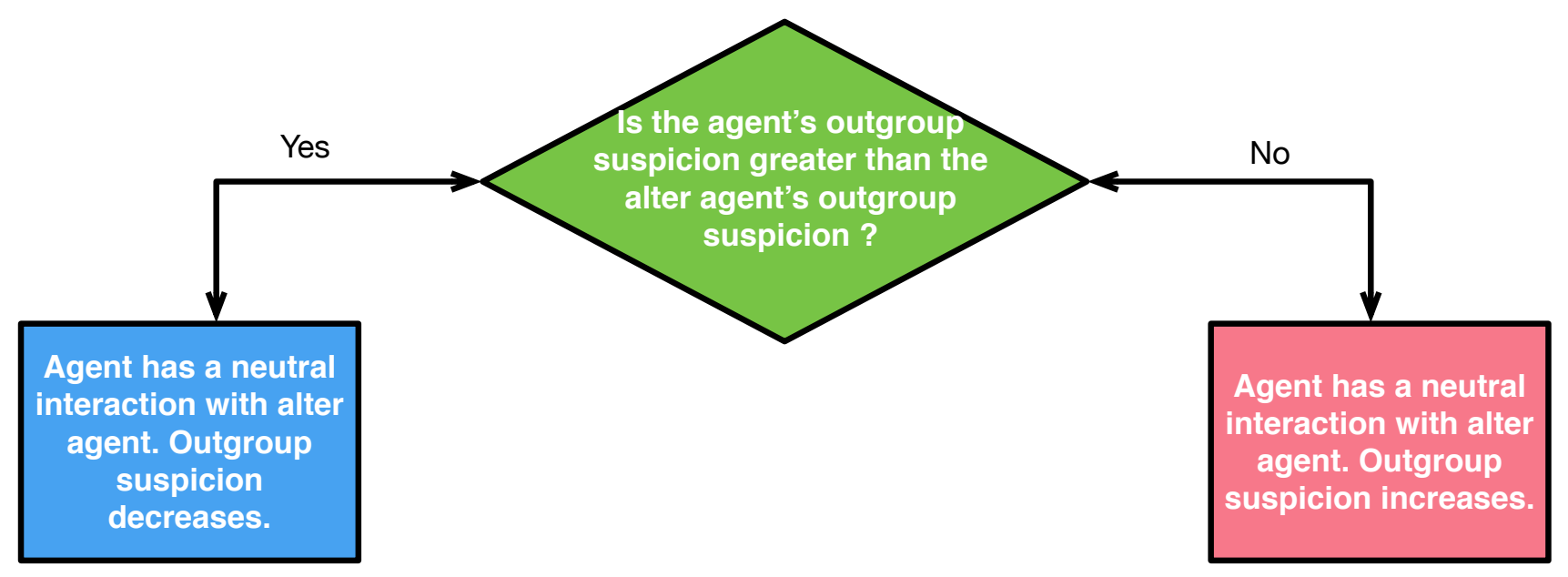

Fig 4. The process by which an agent updates its outgroup suspicion.

\section{Results}

In both the World Values Survey data and the agent-based simulation we pose and answer the following research questions:

1. Do individuals / agents affiliated with a supernatural worldview club exhibit more active pro-sociality than individuals / agents who are not affiliated with a supernatural worldview club? What if tribal active pro-sociality is excluded? What if passive pro-sociality is explored?

2. Do individuals / agents with a supernatural worldview exhibit more active pro-sociality than individuals / agents with a natural worldview? What if tribal active pro-sociality is excluded? What if passive pro-sociality is explored? 


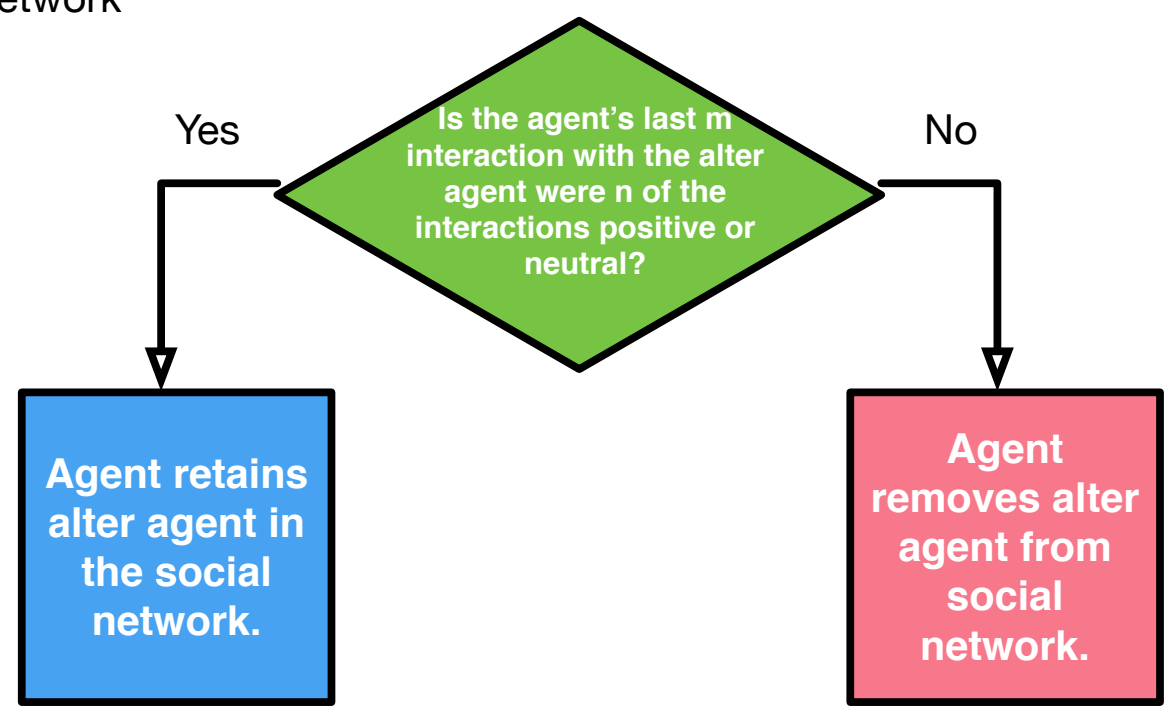

Job, Family and Supernatural Worldview Club Social networks

In these networks an alter can be added or removed. However, the addition or

removal of an alter agent from the social networks in not in the control of the agent.

It has to do with if the alter agent becomes unemployed, dies, or unaffiliates from

the Supernatural Worldview Club.

Fig 5. The process by which an agent removes individuals from its social networks.

3. Do individuals / agents who change their worldview from supernatural to natural demonstrate a different passive pro-sociality profile prior to the change than individuals / agents who change their worldview from natural to supernatural?

4. Do individuals / agents with a supernatural worldview who change their affiliation status from affiliated to unaffiliated with a supernatural worldview club demonstrate a different passive pro-sociality profile prior to the change than individuals / agents with a supernatural worldview who change their affiliation status from unaffiliated to affiliated with a supernatural worldview club?

We answer each research question by analyzing the WVS and running the agent-based simulation. All of the runs from the simulation result from the same parameterization. The parameterization produces a stable population (in terms of death and birth rate), with a $9 \%$ unemployment rate for agents over 18 , where $30 \%$ of the agents are in the minority group. Furthermore, the number of agents of each gender, with a supernatural worldview, natural worldview and affiliation with a supernatural worldview club are all within $5 \%$ of the demographics observed in the WVS data. Each of the results reported in this section reflect the mean statistics computed over 1,000 replications of the simulation. The results for all four research questions are summarized in Table 2 


\section{Supernatural Worldview Club Affiliation Process}

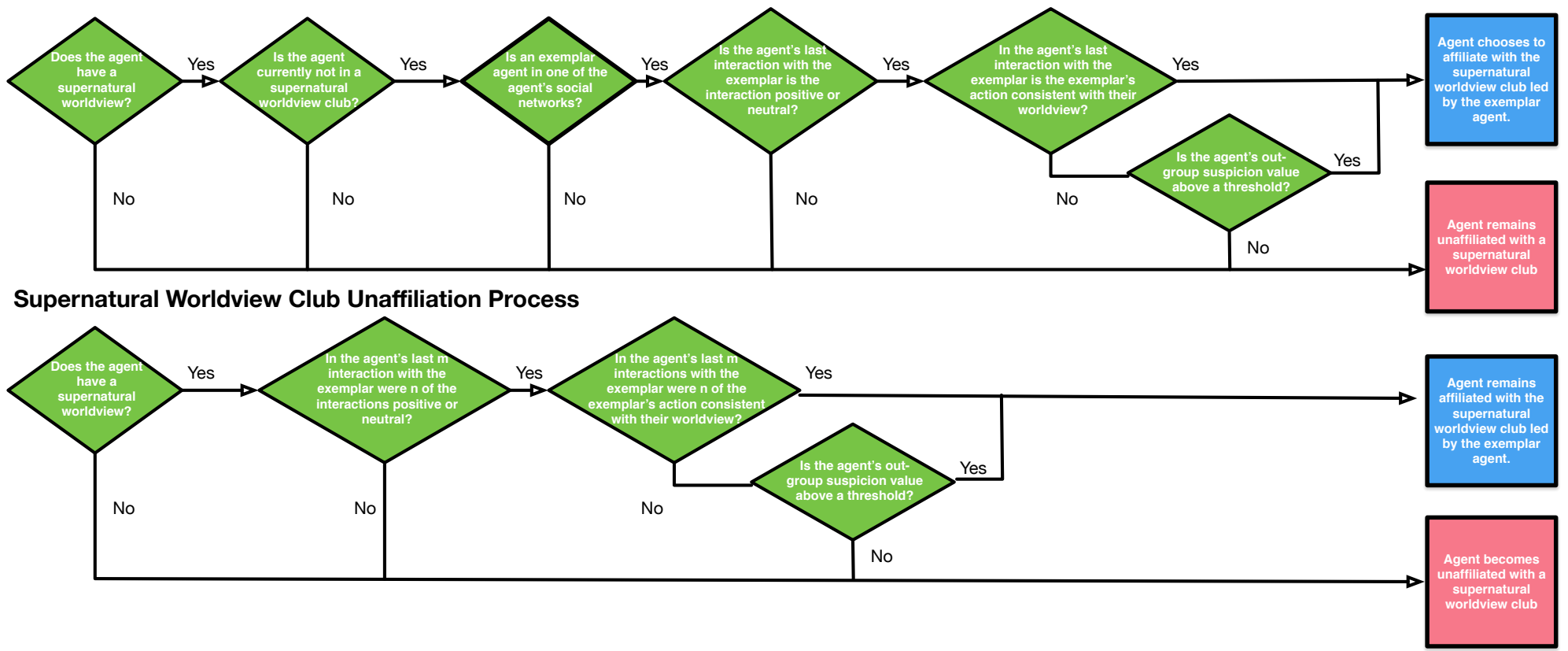

Fig 6. The process by which an agent affiliates or unaffiliates with a supernatural worldview club.

Table 2. Summary of results for Research Questions

\begin{tabular}{|ccccc|}
\hline RQ \# & Method & All Actions & Excluding Tribal Actions & Passive Pro-sociality \\
\hline$\# 1$ & Data Analysis & Yes $(p<0.01)$ & Yes $(p<0.01)$ & Trust - No $(p>0.99) ;$ Tolerance - No $(p>0.99)$ \\
$\# 1$ & Simulation & Yes $(p<0.01)$ & Yes $(p<0.01)$ & Trust - No $(p>0.99) ;$ Tolerance - No $(p>0.99)$ \\
\hline$\# 2$ & Data Analysis & Yes $(p<0.01)$ & No $(p=0.54)$ & Trust - No $(p>0.99) ;$ Tolerance - No $(p>0.99)$ \\
$\# 2$ & Simulation & Yes $(p<0.01)$ & No $(p=0.53)$ & Trust - No $(p>0.99) ;$ Tolerance - No $(p>0.99)$ \\
\hline$\# 3$ & Data Analysis & NA & NA & Trust - No $(p=0.66) ;$ Tolerance - Yes $(p<0.01)$ \\
$\# 3$ & Simulation & NA & NA & Trust - No $(p=0.51) ;$ Tolerance - Yes $(p<0.01)$ \\
\hline$\# 4$ & Data Analysis & NA & NA & Trust - Yes $(p<0.01) ;$ Tolerance - No $(p=0.03)$ \\
$\# 4$ & Simulation & NA & NA & Trust - Yes $(p<0.01) ;$ Tolerance - No $(p=0.04)$ \\
\hline
\end{tabular}

\section{Research Question \#1: Pro-sociality and affiliation with a Supernatural Worldview Club}

Here we present our results for the data analysis of the WVS and the agent-based simulation for Research Question \#1. Our results are summarized in Table 2. In the following subsections we describe our results in more detail and we elucidate how the results are created within the simulation.

\section{Active Pro-sociality}

Within the WVS Data in Wave 2 and Wave 4 (1990-1994 and 1999-2004) an individual affiliated with a supernatural worldview club is more likely than an individual who is not affiliated with a worldview club to be actively pro-social. Among individuals affiliated with a supernatural worldview club, $42.7 \%$ are actively pro-social while only $22.2 \%$ of individuals not affiliated with a supernatural worldview club are actively pro-social. Applying a t-test indicates a statistically significant difference in the average active pro-sociality rate of the two groups with a $p$-value less than 0.01 .

Excluding tribal pro-sociality from the analysis reduces the average rate at which individuals in a supernatural worldview club are actively pro-social (30.4\% instead of $42.7 \%$ ). However, applying a t-test still indicates a statistically significant difference between the average pro-sociality rates of the two groups with a $p$-value less than 0.01 . 
The agent-based simulation yields very similar results. Within the simulation, an agent affiliated with a supernatural worldview club is more likely than an individual who is not affiliated with a worldview club to be actively pro-social. On average across our 1,000 simulation replications, $44.3 \%$ of agents affiliated with a supernatural worldview club are actively pro-social while only $21.0 \%$ of individuals unaffiliated with a supernatural worldview club are actively pro-social.

Applying a t-test indicates a statistically significant difference between the average pro-sociality rate of these two groups with a $p$-value less than 0.01 . When tribal pro-sociality is excluded in the agent based simulation, $31.3 \%$ of agents affiliated with a supernatural worldview club exhibit active pro-sociality which still indicates a statistically significant difference between the average pro-sociality rate of the two groups with a $p$-value less than 0.01 .

It is noteworthy that the agent-based simulation was able to reproduce, within a $2 \%$ margin of error for each group, the results from the WVS data analysis. However, the main contribution provided from the agent-based simulation is its explanation as to why there is a statistically significant difference between the active pro-sociality rate of agents affiliated with a supernatural worldview club and those agents who are not affiliated with a supernatural worldview club, even when tribal pro-social actions are excluded.

Within the simulation agents in supernatural worldview clubs are more likely to have more pro-social actions of all types generated for them because these agents have an additional social network, their supernatural worldview club. Having an additional social network to interact with regularly creates a dynamic where affiliated agents receive more pro-social action opportunities of each type. Thus even though affiliated and unaffiliated agents accept pro-social action opportunities at the same rate, affiliated agents are more regularly presented with pro-social action opportunities resulting in a higher rate of performing all types of pro-social actions.

These dynamics within the simulation are shown in Figure 7. In Figure 7 it is clear that each group accepts non-tribal pro-social action opportunities at the same rate but the affiliated group receives about $15 \%$ more opportunities than the unaffiliated group. These dynamics support the theories that: (1) high quality within-group social contacts, high levels of perceived social support, and strong group identity, are aspects of religious commitment most associated with social capital [42 44]; (2) religious groups or settings increase the ease of social networking [45, 46] and (3) churches promote pro-sociality because of the contextual factor of more pro-social requests 47 .

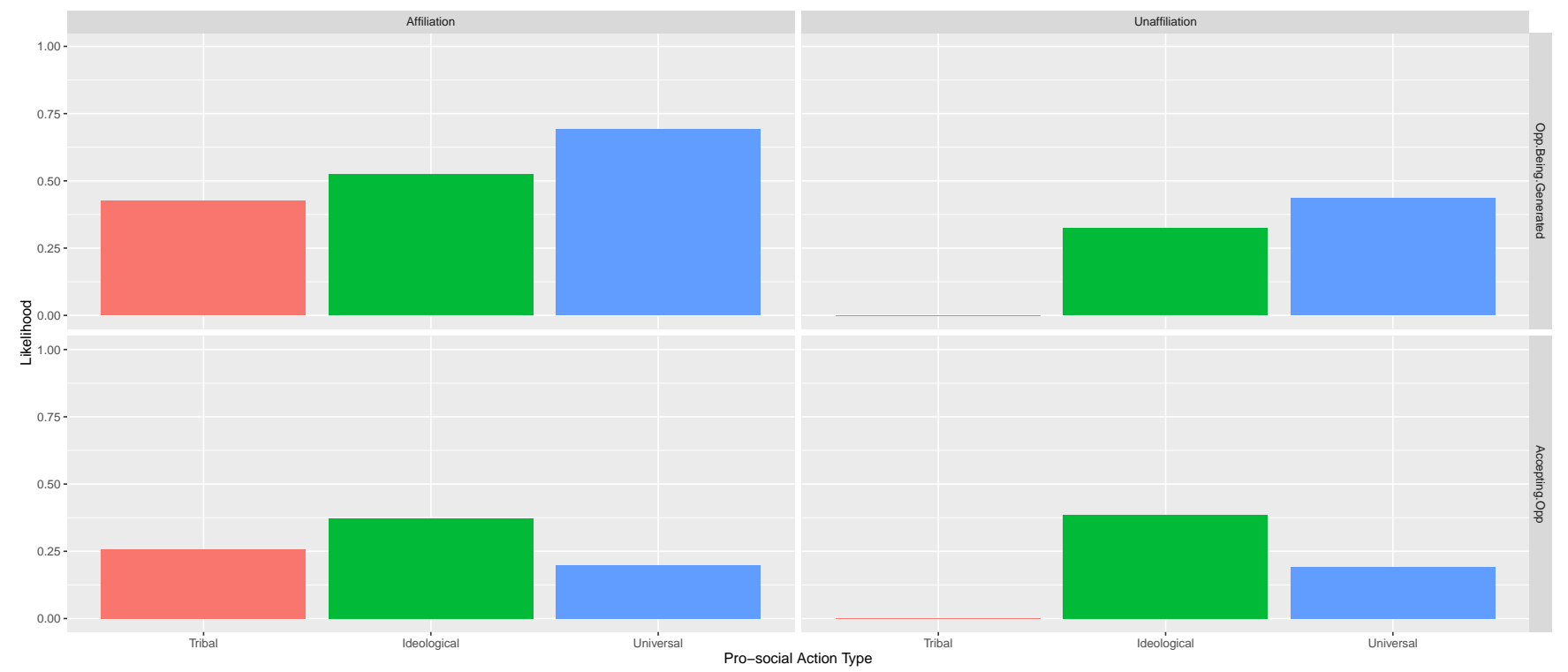

Fig 7. The average likelihood of each type of pro-social action opportunity being generated and accepted for affiliated and unaffiliated agents in the simulation.

\section{Passive Pro-sociality}

In the WVS, an individual that is affiliated with a supernatural worldview club is not more likely than an individual who is not affiliated with a supernatural worldview club to exhibit trust as a form of passive pro-social activity. Among 
individuals who are not affiliated with a supernatural worldview club, $28.0 \%$ exhibit trust while only $26.0 \%$ of individuals who are affiliated supernatural worldview club do so. Applying a t-test to Research Question \#1 does not indicate individuals affiliated with a supernatural worldview club exhibit trust of others at a higher rate than individuals who are not affiliated with a supernatural worldview club. Furthermore, when a t-test is performed on the opposite question, "Do individuals who are not affiliated with a supernatural worldview club exhibit passive pro-sociality related to trust at a higher rate than individuals affiliated with a supernatural worldview club" it indicates a statistically significant difference between the two groups with a $p$-value less than 0.01 .

The agent-based simulation yields results that are similar to the WVS data related to affiliation and passive pro-sociality in the form of trust. Recall, trust is operationalized in the simulation as the total size of all of an agent's social network relative to maximum size of all agent's social networks. This is expressed as a number between 0 and 1 . For example, if the total size of all an agent's social networks is greater than $40 \%$ of the total size of all the social networks for other agents in the simulation then the agent's trust score would be 0.40 . In the simulation the average trust score for agents affiliated with supernatural worldview clubs is 0.46 and the average trust score for agents who are not affiliated with supernatural worldview clubs is 0.54 .

Since the operationalization of trust is so different in the simulation than the WVS it was expected that the values for each group (affiliated - $26.0 \%$ vs. 0.46 and unaffiliated $28.0 \%$ vs. 0.54 ) would be quite different. However, it is noteworthy that the trust values for the two groups in the simulation did not indicate a statistically significant difference when a t-test was applied with respect to Research Question \#1. Furthermore, when the opposite question was asked, "Do agents who are not affiliated with a supernatural worldview club exhibit passive pro-sociality related to trust at a higher rate than agents affiliated with a supernatural worldview club" it indicated a statistically significant difference between the two groups with a $p$-value less than 0.01 .

Within the context of the simulation unaffiliated agents have a larger total social network (and thus higher trust score) than affiliated agents because unaffiliated agents have larger online and offline social networks. The difference in the size of the online and offline social networks occurs because unaffiliated agents are less likely to have negative interactions with outgroup agents, which makes unaffiliated agents less likely to remove outgroup agents from their online and offline social networks.

The extent to which the removal of outgroup agent occurs for affiliated agents is noteworthy because affiliated agents have an additional social network that unaffiliated agents do not have, their supernatural worldview club. However, the rate at which affiliated agents remove outgroup agents from their social network is large enough that it indicates a statistically significant difference between the total social network size for the two groups.

Figure 8 illustrates this dynamic by showing the relative size of each social network for affiliated and unaffiliated agents. While the presence of a supernatural worldview club increases the size of an affiliated agent's social network, the lack of agents in an affiliated agent's online and offline social networks outweighs this increase, resulting in a smaller total social network. It is important to note that both groups have almost the exact same size job, family and neighborhood social networks, on average.

These dynamics within the simulation show that there is an implicit inverse relationship between active pro-sociality and passive pro-sociality in the form of trust. Other previous studies on religious affiliation support these findings, including results showing that religiosity is associated with: (1) ingroup binding but also greater cliquishness, a distrust of outsiders, and an unwillingness to mingle with them [48, 49] and (2) general outgroup distrust [50]. In contrast, previous studies have found nonreligious individuals show greater generalized trust 34,51 .

With respect to tolerance, our other operationalized measure of passive pro-sociality, the results between the World Value Survey data analysis and the agent-based simulation are similar. In the WVS, an individual that is affiliated with a supernatural worldview club is not more likely than an individual who is not affiliated with a supernatural worldview club to exhibit tolerance as a form of passive pro-social activity. Among individuals not affiliated with a supernatural worldview club, $93.2 \%$ exhibit tolerance while only $91.2 \%$ of individuals who are affiliated supernatural worldview club do so. Applying a t-test to Research Question \#1 does not indicate individuals affiliated with a supernatural worldview club exhibit tolerance of others at a higher rate than individuals who are not affiliated with a supernatural worldview club. Furthermore, when a t-test is performed on the opposite question, "Do individuals who are not affiliated with a supernatural worldview club exhibit passive pro-sociality related to tolerance at a higher rate than individuals affiliated with a supernatural worldview club" it indicates a statistically significant difference between the two groups with a $p$-value less than 0.01 .

Recall in the agent-based simulation, tolerance is operationalized in the simulation as 1 - the agent's outgroup 


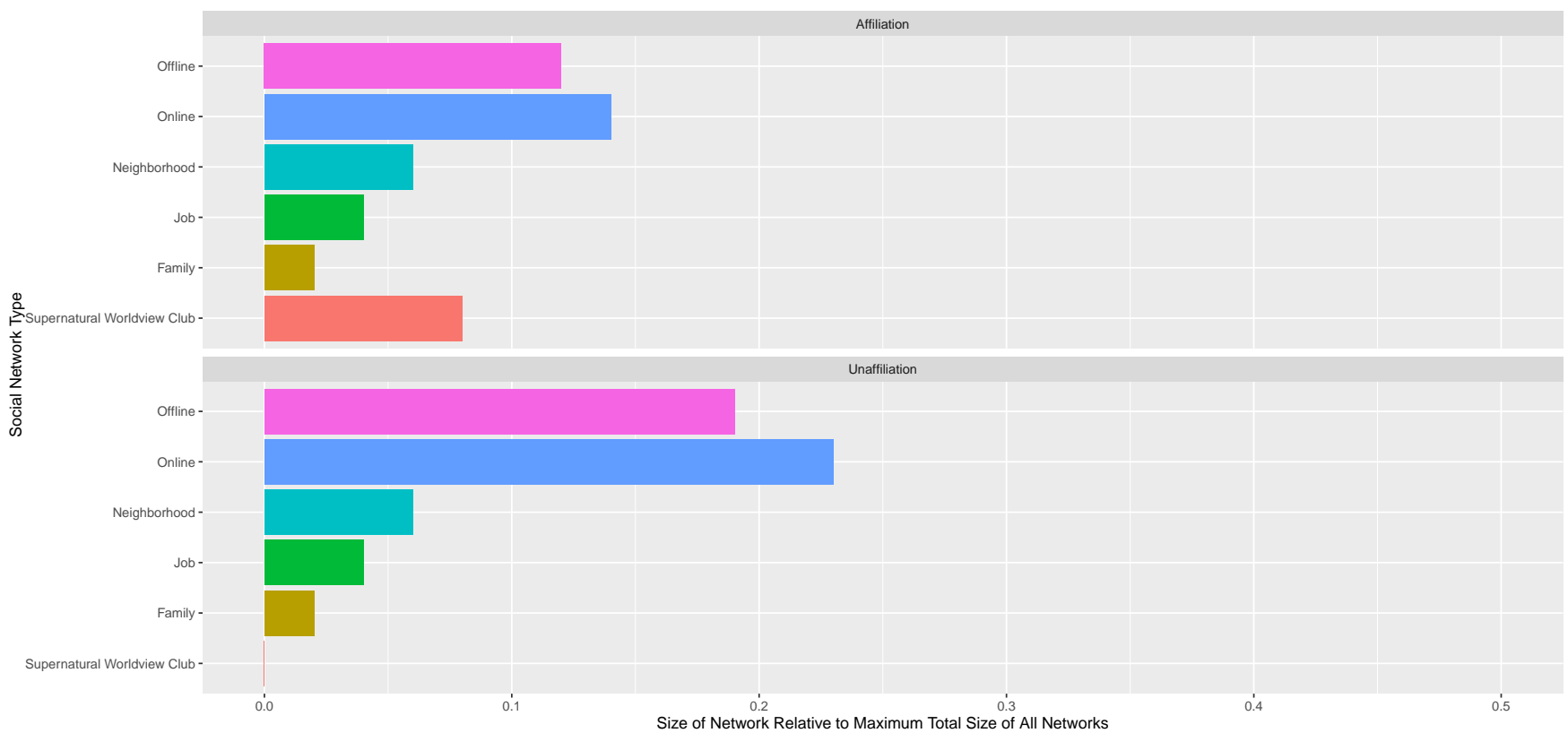

Fig 8. The size of each type of social network relative to maximum total size of all social networks for an agent in the simulation, separated into agents affiliated with a supernatural worldview club and an unaffiliated agents.

suspicion. Outgroup suspicion is expressed as a number between 0 and 1 , so a tolerance value of 1 reflects an agent with no outgroup suspicion and a tolerance value of 0 reflects an agent with suspicion of all members of the outgroup. In the simulation the average tolerance score for agents affiliated with supernatural worldview clubs is 0.72 and the average tolerance score for agents who are not affiliated with supernatural worldview clubs is 0.79 . When a t-test is applied to the simulation data related to tolerance with respect to Research Question \#1 it does not indicate a statistically significant difference between the two groups. Furthermore, when the opposite question is asked, "Do agents who are not affiliated with a supernatural worldview club exhibit passive pro-sociality related to tolerance at a higher rate than agents affiliated with a supernatural worldview club" it indicates a statistically significant difference between the two groups with a $p$-value less than 0.01 .

In the simulation this difference occurs because outgroup suspicion is one of the conditions (when present with several others) that may lead an agent to affiliate with a supernatural worldview club. This creates a social network for an affiliated agent where the average member is likely to have a higher outgroup suspicion values than the rest of the agent population. Furthermore, the interactions that take place in this social network are likely to increase or maintain an agent's outgroup suspicion value because the majority-majority or minority-minority interactions with the supernatural worldview club social network are with agents likely to have higher than average levels of outgroup suspicion. These dynamics are highlighted in Figure 9 which shows the extent to which an agent's outgroup suspicion value is increased or decreased during the time the agent is affiliated with a supernatural worldview club. The figure shows that in almost all cases the outgroup suspicion level of an agent increases during the agent's time period being affiliated with a supernatural worldview club and the average increase in an affiliated agent's outgroup suspicion is $\sim 0.065$.

These dynamics are congruous with previous studies showing that the social bonding and capital within groups of supernatural worldview club members is linked to intolerance of others as observed by [52] and, in general, people who are religiously affiliated are more prejudiced toward outgroups [53 56]. Furthermore, the role homophily plays (majority-majority or minority-minority interactions) within the simulation to drive outgroup suspicion in supernatural worldview clubs mirrors research findings that greater church attendance is associated with parochialism and homophily 45. 


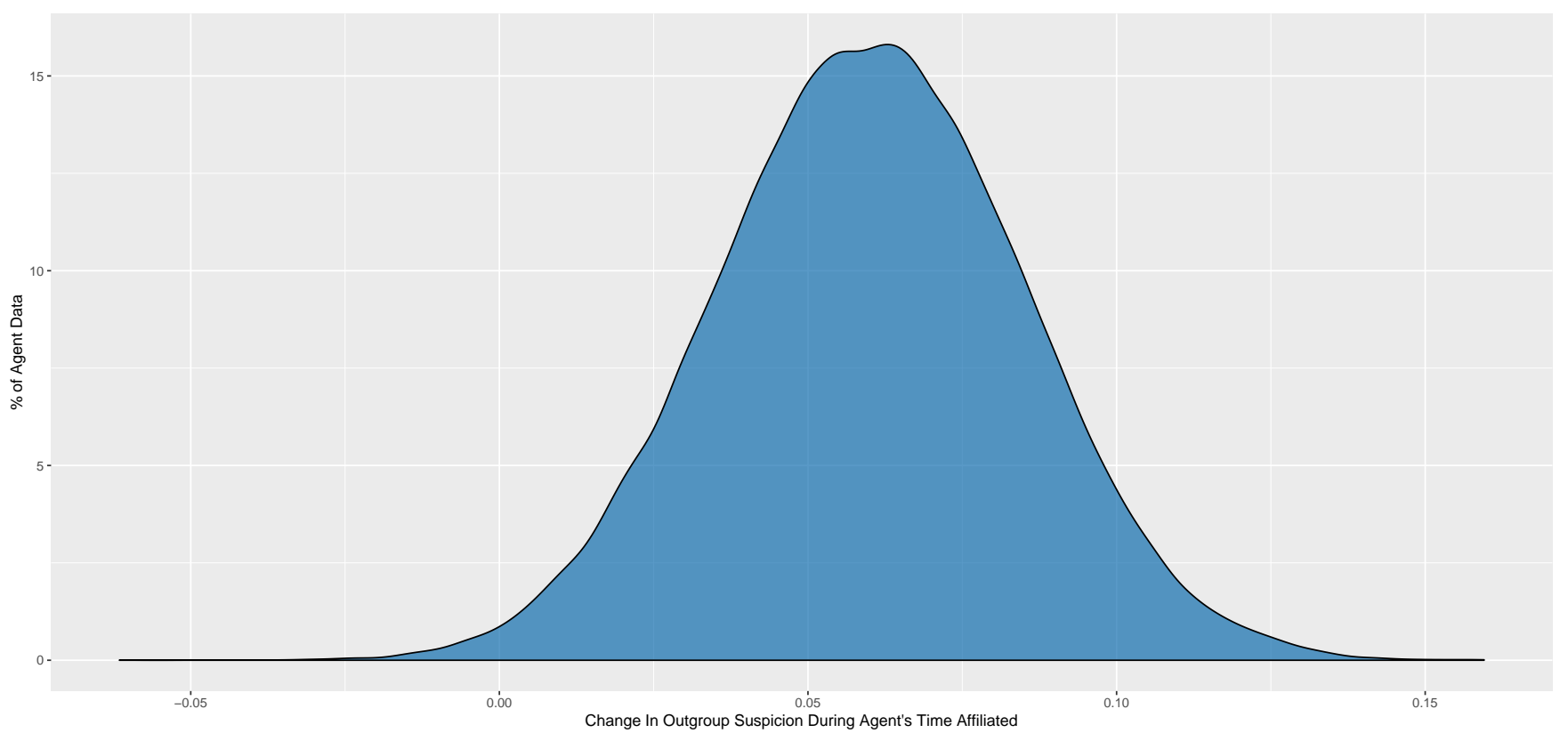

Fig 9. The change in outgroup suspicion of agents during their time affiliated with supernatural worldview clubs in the simulation.

\section{Research Question \#2: Pro-sociality and Worldview}

Here we present our results for the data analysis of the WVS and the agent-based simulation for Research Question \#2. Our results are summarized in Table 2. In the following subsections we describe our results in more detail and we elucidate how the results are created within the simulation.

\section{Active Pro-sociality}

Within the WVS Data in Wave 2 and Wave 4 (1990-1994 and 1999-2004) an individual with a supernatural worldview is more likely than an individual with a natural worldview to be actively pro-social. Among individuals with a supernatural worldview $32.4 \%$ are actively pro-social while only $26.2 \%$ of individuals with a natural worldview are actively pro-social. Applying a t-test indicates a statistically significant difference in the active pro-sociality rate of the two groups with a $p$-value less than 0.01 .

Excluding tribal pro-sociality from the analysis changes the rate (26.1\% instead of $32.4 \%)$ at which individuals with a supernatural worldview are actively pro-social. Under these conditions the rate of active pro-sociality between the two groups is almost the same (supernatural - 26.1\%; natural - 26.2\%). Thus, applying a t-test does not indicate a statistically significant difference between individuals with a supernatural worldview and individuals with a natural worldview $(p=0.54)$.

The agent-based simulation yields very similar results. Within the simulation, an agent with a supernatural worldview is more likely than an individual with a natural worldview to be actively pro-social. On average across our 1,000 simulation replications, $31.7 \%$ of agents with a supernatural worldview are actively pro-social while only $26.8 \%$ of individuals with a natural worldview are actively pro-social. Applying a t-test results in a statistically significant difference between the pro-sociality rate of these two groups with a $p$-value less than 0.01 . However, when tribal pro-sociality is excluded in the agent based simulation both groups exhibit active pro-sociality at almost exactly the same rate (26.81\% - supernatural; $26.82 \%$ natural). Given the almost identical rate between the two groups, applying a t-test does not indicate a statistically significant difference $(p=0.53)$.

Once again, it is noteworthy that the agent-based simulation was able to reproduce, within a $<1 \%$ margin of error for each group, the results from the WVS data analysis. However, the main contribution is the explanation as to why there is a statistically significant difference between the active pro-sociality rate of agents with a supernatural worldview and a 
natural worldview when tribal pro-sociality is included but not when tribal pro-sociality is excluded.

Recall, within the simulation an agent is required to have a supernatural worldview to be affiliated a supernatural worldview club. Furthermore, recall that only agents affiliated with a supernatural worldview club have tribal pro-social actions generated for them. Thus, since some of the agents with a supernatural worldview have an additional source of pro-social action opportunities (i.e. tribal ones) this creates a dynamic where agents with a supernatural worldview, on average, receive more pro-social action opportunities.

This dynamic disappears when tribal pro-social actions are excluded from the analysis. Initially, this seems unexpected. Recall, even when excluding tribal pro-sociality, individuals affiliated with a supernatural worldview club were more pro-socially active than unaffiliated individuals. Given that the group of individuals with a supernatural worldview includes those individuals affiliated with a supernatural worldview club one might expect this group to be more pro-socially active than individuals with a natural worldview. However, this is not true; instead the two groups exhibit active pro-sociality at the same rate.

This occurs because unaffiliated individuals with a supernatural worldview are the least pro-socially active group compared to affiliated individuals and individuals with a natural worldview. The lack of active pro-sociality in unaffiliated individuals occurs because the group has higher outgroup suspicion than individuals with a natural worldview. This higher outgroup suspicion value limits the size of the online and offline social networks unaffiliated individuals have.

The higher outgroup suspicion value is caused by the inclusion of individuals who recently left a supernatural worldview club due to: (1) negative interactions with members of the club or (2) inconsistent actions from the exemplar paired with an outgroup suspicion value that is below the specified threshold. The time these individuals spent with the worldview club increased their outgroup suspicion as shown in Figure 9. Furthermore, even in cases where the individual's outgroup suspicion has decreased during the time away from the supernatural worldview club (i.e. their outgroup suspicion value no longer meets the specified threshold) the value is still likely to be above the average outgroup suspicion value for an agent who was never affiliated with a supernatural worldview club. In other words, the agent is still more suspicious of the outgroup than the average unaffiliated agent but the agent is not sufficiently suspicious of the outgroup for this to be part of their reason to join in a supernatural worldview club.
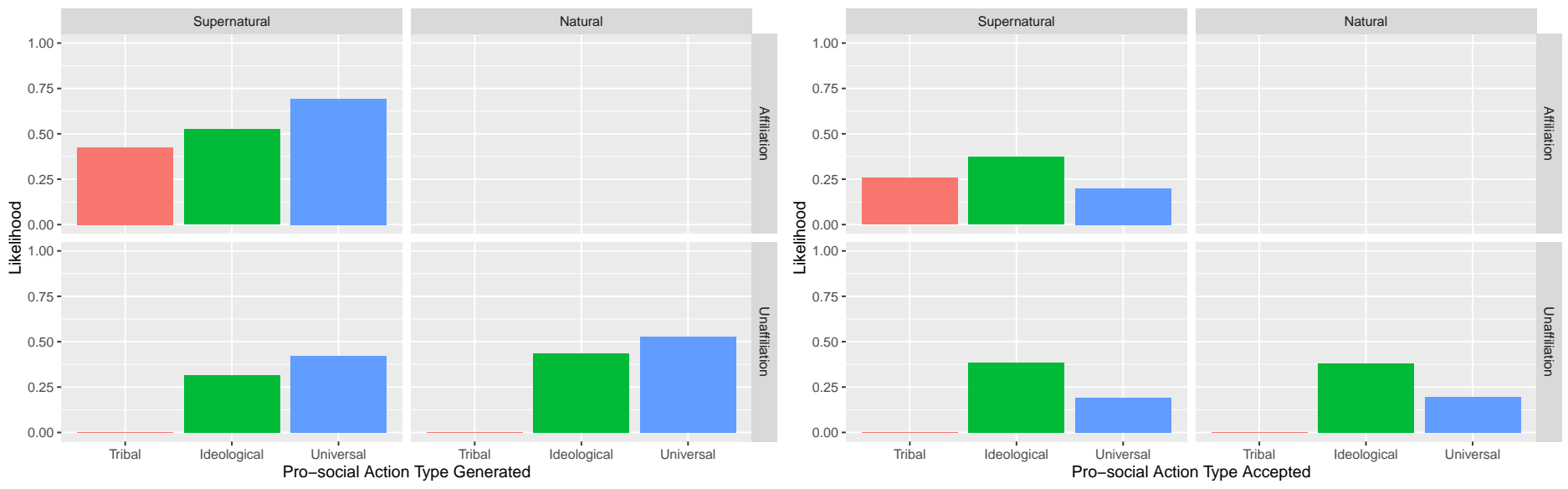

Fig 10. The likelihood of each type of pro-social action opportunity being generated for and being accepted by an agent based on the agent's worldview and affiliation status.

Figures 10 shows that all three groups accept pro-social action opportunities at the same rate. However, the figure also shows significantly fewer opportunities are generated for unaffiliated individuals with a supernatural worldview. Figure 11 illustrates that fewer opportunities are generated because these individuals lack a supernatural worldview club social network and they have smaller online and offline social networks relative to unaffiliated individuals with a natural worldview. The result is that unaffiliated individuals with a supernatural worldview are the least pro-socially active group.

These findings combined with our results from Research Question \# 1 show evidence that affiliation with a supernatural worldview club is much more important for active pro-sociality than a supernatural worldview. This mirrors previous results showing that frequent attendance in religious organizations is a stronger predictor of volunteering than belief-related factors 57,58$]$ and factors such as social networking, rather than belief content appear to be the mechanism 


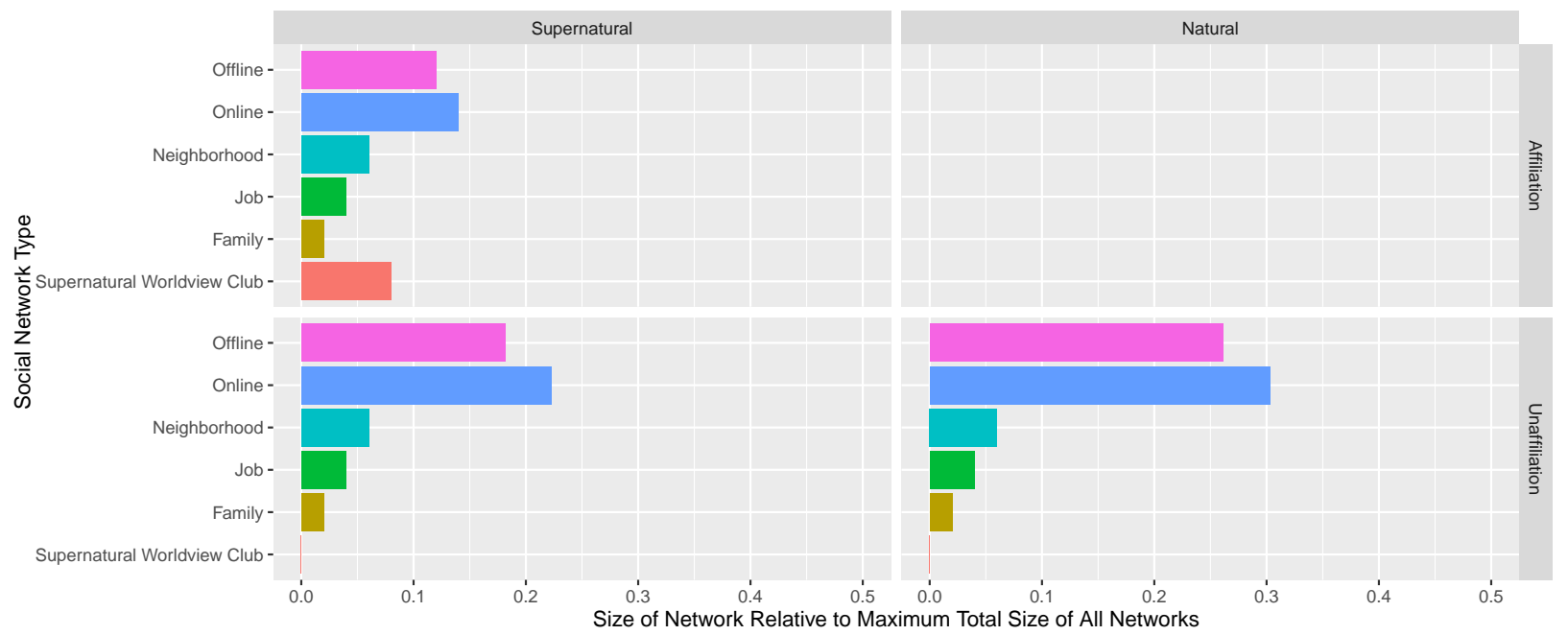

Fig 11. The average size of an agent's social network based on their worldview and affiliation status.

driving volunteerism $[59$.

\section{Passive Pro-sociality}

In the WVS, an individual with a supernatural worldview is not more likely than an individual with a natural worldview to exhibit trust as a form of passive pro-social activity. Among individuals with a natural worldview, $36.6 \%$ exhibit trust while only $26.1 \%$ of individuals with supernatural worldview do so. Applying a t-test to Research Question \#2 does not indicate individuals with a supernatural worldview exhibit trust of others at a higher rate than individuals natural worldview. Furthermore, when a t-test is performed on the opposite question, "Do individuals who with a natural worldview exhibit passive pro-sociality related to trust at a higher rate than individuals with a supernatural worldview" it indicates a statistically significant difference between the two groups with a $p$-value less than 0.01 .

The agent-based simulation yields results that are similar to the WVS data related to worldview and passive pro-sociality in the form of trust. In the simulation the average trust score for agents with a supernatural worldview is 0.49 and the average trust score for agents with a natural worldview is 0.68 .

Since the operationalization of trust is so different in the simulation than the WVS it was expected that the values for each group (supernatural worldview $26.1 \%$ vs. 0.49 and natural worldview $36.6 \%$ vs. 0.68 ) would be quite different.

However, it is noteworthy that the trust values for the two groups in the simulation did not indicate a statistically significant difference when a t-test was applied with respect to Research Question \#2. Furthermore, when the opposite question was asked, "Do agents who with a natural worldview exhibit passive pro-sociality related to trust at a higher rate than agents with a supernatural worldview" it indicated a statistically significant difference between the two groups with a $p$-value less than 0.01 .

Within the context of the simulation, agents with a natural worldview have a larger total social network (and thus higher trust score) than affiliated agents because unaffiliated agents have larger online and offline social networks. This is shown in Figure 11. The difference in the size of the online and offline social networks occurs because agents with a natural worldview are less likely to have negative interactions with outgroup agents because they have less outgroup suspicion. This makes agents with a natural worldview less likely to remove outgroup agents from their online and offline social networks.

The extent to which the removal of outgroup agent occurs for agents with a supernatural worldview is noteworthy, just as it was for affiliated agents in Research Question \#1. This is noteworthy because some agents with a supernatural worldview have an additional social network that agents with a natural worldview do not have, a supernatural worldview club. However, the rate at which agents with a supernatural worldview, including affiliated agents, remove outgroup agents from their social network is large enough that it indicates a statistically significant difference between the total social network size for agents with supernatural worldview versus agents with a natural worldview. 
Figure 11 illustrates this dynamic by showing the relative size of each social network for agents broken down by worldview and affiliation. While the presence of a supernatural worldview club increases the size of an affiliated agent's social network, the lack of agents in an affiliated agent's online and offline social networks outweighs this increase resulting in a smaller total social network overall. Furthermore, for those unaffiliated agents with a supernatural worldview their online and offline social networks are still smaller than those of an agent with a natural worldview. This is because of the inclusion of individuals who recently left a supernatural worldview club due to: (1) negative interactions with the exemplar agent in the club or (2) inconsistent actions from the exemplar paired with an outgroup suspicion value that is below the specified threshold. As discussed in the Research Question \#2 Active Pro-sociality Subsection this results in above average outgroup suspicion for unaffiliated agents with a supernatural worldview which creates smaller online and offline social networks than individuals with a natural worldview.

With respect to tolerance, our other operationalized measure of passive pro-sociality, the results between the World Value Survey data analysis and the agent-based simulation are similar. In the WVS, an individual with a supernatural worldview is not more likely than an individual with a natural worldview to exhibit tolerance as a form of passive pro-social activity. Among individuals with a natural worldview, 94.0\% exhibit tolerance while only $92.1 \%$ of individuals with a supernatural worldview do so. Applying a t-test to Research Question \#2 does not indicate individuals with a supernatural worldview exhibit tolerance of others at a higher rate than individuals with a natural worldview.

Furthermore, when a t-test is performed on the opposite question, "Do individuals with a natural worldview exhibit passive pro-sociality related to tolerance at a higher rate than individuals with a supernatural worldview" it indicates a statistically significant difference between the two groups with a $p$-value less than 0.01 .

In the simulation the average tolerance score for agents with supernatural worldview is 0.78 and the average tolerance score for agents with a natural worldview is 0.86 . When a t-test is applied to the simulation data related to tolerance with respect to Research Question \#2 it does not indicate a statistically significant difference between the two groups. Furthermore, when the opposite question is asked, "Do agents with a natural worldview club exhibit passive pro-sociality related to tolerance at a higher rate than agents associated with a supernatural worldview" it indicates a statistically significant difference between the two groups with a $p$-value less than 0.01 .

In the simulation this difference occurs because the group of individuals with a supernatural worldview includes: (1) affiliated individuals with a supernatural worldview club and (2) individuals who were part of a supernatural worldview club but unaffiliated and (3) other unaffiliated individuals with a supernatural worldview who never affiliated. Recall, that affiliated individuals have a lower tolerance score than unaffiliated agents. However, even among unaffiliated agents those with a supernatural worldview have a lower tolerance score than unaffiliated agents with a natural worldview. This occurs because most agents who used to be affiliated with a supernatural worldview club become those with a supernatural worldview as opposed to agents with a natural worldview. These agents who used to be affiliated with a supernatural worldview club have a higher outgroup suspicion value (and thus lower tolerance score) than agents who have never been affiliated with a supernatural worldview club.

In the simulation it takes a significant amount of time for agents who were affiliated with a worldview club to dramatically change their outgroup suspicion value. Figure 12 shows the average change in the outgroup suspicion value of an agent as a function of weeks (i.e. time steps) within the simulation. The blue line in the figure represents a smoothed curve interpolated from the points. The figure shows it takes 40 weeks (almost 1 year) for an agent to reduce their outgroup suspicion 0.05 units and 65 weeks ( 1 year and 3 months) to reduce their outgroup suspicion 0.10 units. This is noteworthy because it shows that there is a tipping point period of time that must pass before there is a large magnitude change in the outgroup suspicion of previously affiliated individuals. Since most of these individuals retain their supernatural worldview rather than switch to a natural worldview, it increases the average outgroup suspicion (and thus decreases the tolerance) of unaffiliated individuals with a supernatural worldview.

\section{Research Question \#3: Do changes in passive pro-sociality precede changes in worldview?}

Here we present our results for the data analysis of the WVS and the agent-based simulation for Research Question \#3. Our results are summarized in Table 2, In what follows we describe our results in more detail and we elucidate how the results are created within the simulation.

Within the context of the longitudinal data in the WVS there is not a statistically significant difference $(p=0.66)$ between the passive pro-sociality rate, related to trust, of individuals who change their worldview from supernatural to 


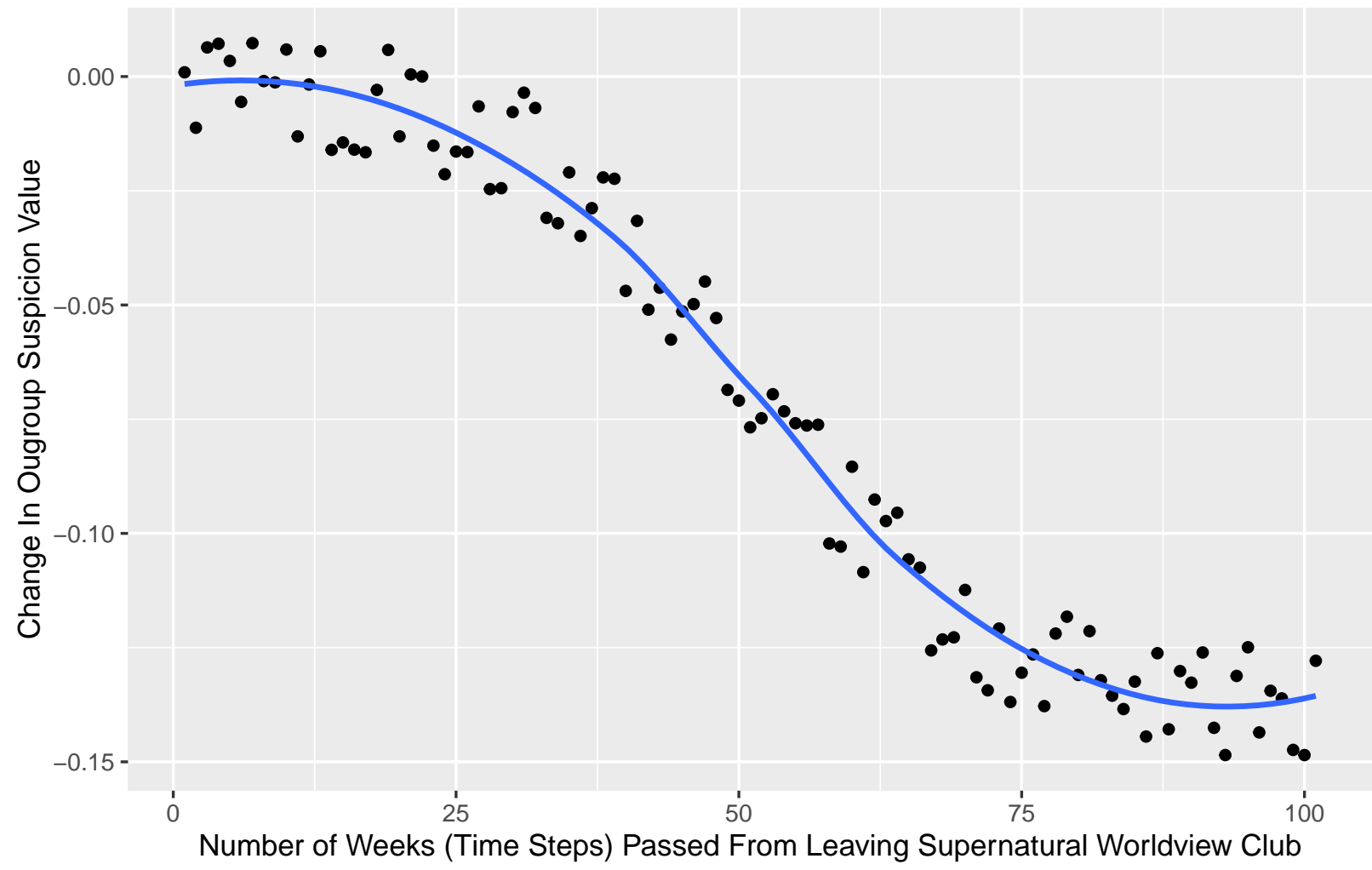

Fig 12. The average change in an agent's outgroup suspicion after disaffiliating with a supernatural worldview club.

natural (35.4\%) and individuals who change their worldview from natural to supernatural (34.9\%). However, an individual who changes their worldview from supernatural to natural is more likely to exhibit passive pro-sociality in the form of tolerance prior to the change than individuals who change their worldview from natural to supernatural. Among individuals who change their worldview from supernatural to natural, $94.3 \%$ exhibit passive pro-sociality in the form of tolerance prior to the change while only $92.1 \%$ of individuals who change their worldview from natural to supernatural exhibit passive pro-sociality in the form of tolerance prior to the change. This indicates a statistically significant difference in the passive pro-sociality rate, related to tolerance, of the two groups $(p<0.01)$.

Within the context of the simulation we distinguish between agents who change their worldview from supernatural to natural and agents who change their worldview from natural to supernatural using the following criteria: the agent must have had their previous worldview for 26 weeks (i.e. 26 time steps) prior to the worldview change and must keep their new worldview for 26 weeks after the worldview change. Data collection for the passive pro-sociality prior to the worldview change reflects the average trust and tolerance score during the 26 weeks prior to the agent's worldview change.

Within the agent-based simulation the same patterns observed in the WVS longitudinal data are exhibited. There is not a statistically significant difference $(p=0.51)$ between the passive pro-sociality rate, related to trust between agents who change their worldview from supernatural to natural (0.51) and agents who change their worldview from natural to supernatural (0.51). However, an agent who changes their worldview from supernatural to natural is more likely to exhibit passive pro-sociality, in the form of tolerance prior to the change than agents who change their worldview from natural to supernatural. Agents who change their worldview from supernatural to natural exhibit passive pro-sociality in the form of tolerance prior to the change with a score of 0.84 while agents who change their worldview from natural to supernatural exhibit passive pro-sociality in the form of tolerance prior to the change only with a score of 0.78 . This indicates a statistically significant difference in the passive pro-sociality rate, related to tolerance, of the two groups $(p<0.01)$.

In the simulation there is a difference in the passive pro-sociality profile of agents related to tolerance but not trust before a worldview change because of the two processes which emerge. The first process reflects how agents transition to 
a natural worldview. Within the simulation, it is much more likely for a supernatural agent who is unaffiliated to transition to a natural worldview (92\% of transitions to natural worldview) than for an affiliated agent to transition to a natural worldview ( $8 \%$ of transitions to a natural worldview). Recall from Figure 8, affiliation in a supernatural worldview club provides an agent with an additional social network (the worldview club) and smaller online and offline social networks. In addition, the simulation is parameterized so that an agent is more likely than not to act in a manner consistent with their worldview. Manifested together these conditions reduce the chance than an agent in a supernatural worldview club will have many encounters in which the agent will be conflicted about their worldview. As a result, it is unlikely that an agent in a supernatural worldview club will leave the club because their worldview changed. Thus, usually an agent leaves the supernatural worldview club due to negative interactions with the exemplar agent or having sufficiently low outgroup suspicion and observing the exemplar act in a manner inconsistent with their worldview.

Due to this process almost all agents who transition from a supernatural worldview to a natural worldview are unaffiliated. The transition process from supernatural to natural reflects a series of encounters which make the agent conflicted about their worldview. Because the agents enduring these encounters are unaffiliated they have, on average, lower outgroup suspicion values than affiliated agents. As a result, these agents have a better chance of having positive interactions with alter agents of a different majority/minority distinction. This continues to decrease their outgroup suspicion and maintains the size of their online and offline social networks. As a result the agent's chances of having a future interaction that will make them conflicted about their supernatural worldview increases. Ultimately, the agent experiences enough encounters where they are conflicted about their supernatural worldview that their worldview changes to natural.

The second process that emerges reflects how agents transition from a natural worldview to a supernatural worldview. Every agent that transitions from a natural worldview to a supernatural worldview is initially not affiliated with a supernatural worldview club. This occurs because having a supernatural worldview is a precondition to affiliating with a supernatural worldview club. However, a behavior emerges from the simulation: more than half the time after an agent with a natural worldview transitions to a supernatural worldview the agent joins a supernatural worldview club within 26 time steps following the transition.

This occurs because most of the interactions (68\%) that cause these agents to become conflicted with their natural worldview occur with homophilous agents (in terms of minority/majority) who have a relatively high average outgroup suspicion value (0.28). Interactions between homophilous agents with differing worldviews and higher than average outgroup suspicion increase the outgroup suspicion of the agent with the natural worldview. This interaction dynamic changes the agent's worldview and outgroup suspicion but does not dramatically impact the size of the agent's social network since the interactions with the homophilous agent are not negative. The result is that within 26 time steps after the agent changes their worldview, more than half of the transitioned agents have an outgroup suspicion value that qualifies them to become affiliated with a supernatural worldview club, even if the exemplar agent acts inconsistently with his or her worldview. This results in most of those agents joining a supernatural worldview club.

In combination these two simulation dynamics result in a situation where agents with a natural worldview increase their outgroup suspicion but hold the size of their social networks relatively steady as they begin to transition towards a supernatural worldview through homophilous interactions (in terms of majority/minority) with supernatural agents who have higher than average outgroup suspicion. On the other hand agents who transition from a supernatural worldview to a natural worldview to do so through positive interactions with heterogenous (in terms of majority/minority) natural agents. These interactions decrease the agent's outgroup suspicion and maintain the size of their social network as they transition towards a natural worldview. The simulation enables this explanation of the same patterns related to passive pro-sociality prior to a change in worldview.

\section{Research Question \#4: Do changes in passive pro-sociality precede changes in affiliation with worldview clubs?}

Here we present our results for the data analysis of the WVS and the agent-based simulation for Research Question \#4. Our results are summarized in Table 2, In what follows we describe our results in more detail and we elucidate how the results are created within the simulation.

Within the context of the longitudinal data in the WVS an individual with a supernatural worldview who changes their affiliation status from affiliated to unaffiliated with a supernatural worldview club is more likely to exhibit passive pro-sociality in the form of trust prior to the change in affiliation status than an an individual with a supernatural 
worldview who changes their affiliation status from unaffiliated to affiliated. Among individuals who change their affiliation status from affiliated to unaffiliated, $22.5 \%$ exhibit passive pro-sociality in the form of trust prior to the change while only $18.5 \%$ of individuals who change their affiliation status from unaffiliated to affiliated exhibit passive pro-sociality in the form of trust prior to the change. This indicates a statistically significant difference in the passive pro-sociality, related to trust, of the two groups $(p<0.01)$.

There is not a statistically significant difference $(p=0.028)$ between the passive pro-sociality rate, related to tolerance, between individuals with a supernatural worldview who change their affiliation status from affiliated to unaffiliated with a supernatural worldview club $(90.8 \%)$ and individuals who change their affiliation status from unaffiliated to affiliated with a supernatural worldview club $(92.0 \%)$.

Within the context of the simulation we distinguish between agents who change their affiliation status but maintain a supernatural worldview using the following criteria: the agent must have had a supernatural worldview and their affiliation status for 26 weeks (i.e. 26 time steps) prior to the affiliation change and must keep their new affiliation status and a supernatural worldview for 26 weeks after the affiliation change. Data collection for the passive pro-sociality prior to the affiliation status change reflects the average trust and tolerance score during the 26 weeks prior to the agent's affiliation status change.

Within the agent-based simulation the same patterns related to statistical significance observed in the WVS longitudinal data are exhibited. There is a statistically significant difference $(p<0.01)$ between the passive pro-sociality rate, related to trust, observed before a change in affiliation status for agents with a supernatural worldview. Specifically, prior to the change, agents who change their affiliation status from affiliated to unaffiliated exhibit more trust (0.51) than agents who change their affiliation status from unaffiliated to affiliated (0.44). In contrast, there is not a statistically significant difference in the passive pro-sociality rate, related to tolerance, observed before a change in affiliation status for agents with a supernatural worldview $(p=0.041)$. Supernatural agents who change their affiliation status from affiliated to unaffiliated have an average tolerance score of 0.73 prior to their change while agents who change their affiliation status from unaffiliated to affiliated have a tolerance score of 0.74 prior to the change.

In the simulation these patterns emerge because both groups of agents have low tolerance values (and thus high outgroup suspicion values) prior to their change. Recall, the interactions resulting from affiliation in a supernatural worldview club, even for those affiliated agents who eventually become unaffiliated, limit their tolerance values. Furthermore, the majority (64\%) of unaffiliated agents with a supernatural worldview who become affiliated, do so because the agent achieves an outgroup suspicion value that is sufficiently high to qualify them for affiliation, even if the exemplar agent acts in a manner inconsistent with a supernatural worldview. The 26 weeks of collected tolerance data for these unaffiliated agents who become affiliated shows their tolerance value steadily decreasing as their decision to become affiliated approaches. As a result there is not a statically significant difference in the tolerance values of unaffiliated agents who become affiliated and the tolerance values for those affiliated agents who eventually choose to become unaffiliated.

The low tolerance (and thus high outgroup suspicion) for both groups results in smaller online and offline social networks. However, those individuals who are affiliated prior to their change have an additional social network that the unaffiliated agents do not have: their supernatural worldview club. This additional network results in a larger trust score for the affiliated agents before the agents choose to become unaffiliated. Since unaffiliated agents do not have this additional social network before they choose to become affiliated these agents initially have a a lower average trust score.

\section{Discussion}

Here we discuss construct, internal, and external validity threats and other limitations that affect our work.

\section{Construct validity}

Threats to construct validity concern the appropriateness of the measures used to represent the entities in our simulation. Within the simulation, the representation of both the passive pro-sociality dimensions is different from the questions asked in the WVS. Recall, the WVS asks an individual if people can generally be trusted while the simulation uses a normalized measure of total social network size to represent trust. While the dynamics of the simulation have agents actively remove other agents with whom they have a sufficient number of negative interactions, this is not the same as a binary response about generally trusting others. However, representing trust in this manner allows us to grow the patterns observed in the WVS without explicitly programming a variable to represent if an agent trusts other agents. 
Similarly, the WVS asks an individual if they would not like certain other demographic groups as neighbors while the simulation uses a variable which measures the extent to which an agent is suspicious of members of the other group.

Recall, groups reflect a majority/minority distinction. Thus, for a majority agent, outgroup suspicion reflects the extent to which the agent is suspicious of members of the minority group and for a minority agent outgroup suspicion reflects the extent to which the agent is suspicious of members of the majority group. While this is different from the WVS, representing tolerance in this manner enables us to construct rules about how individuals affiliate with supernatural worldview clubs with respect to their tolerance and how tolerance influences trust (i.e. total social network size).

In both cases, while representing passive pro-sociality in the simulation differently from the WVS threatens construct validity it enables us to grow an explanation as to why patterns related to worldview, affiliation, active pro-sociality and passive pro-sociality emerge. This is one of the major contributions of our work making it an acceptable trade-off.

\section{Internal and external validity}

Internal validity threats arise when factors affect the dependent variables without the researchers' knowledge. It is possible that some implementation flaws could have affected our results for either the WVS data analysis or the implementation of our simulation or ensuing data analysis. However, the algorithms we used to do our analysis and implement our simulation passed several internal code reviews and the results reported for our simulation reflect the mean statistics computed over 1,000 replicated runs of the simulation.

Threats to external validity occur when the results of our analysis and our simulation cannot be generalized. Although the data analysis was performed for using multiple years of data from a very well known source and the simulation is an established model built for the purpose of studying research questions like our own, our results cannot be generalized to: (1) other data sets, (2) different years of the WVS or (3) different agent-based simulations.

\section{Limitations / Re-stating the goal of the simulation}

It is important to emphasize that we are not claiming that our simulation is the most accurate model of the WVS Data. We have not evaluated our simulation against any other competing models. However, the simulation does match the patterns of the WVS in terms of statistical significance and, furthermore, by generating those patterns in an artificial society it provides an explanation as to why they occur, and a new platform on which to explore the relationships among affiliation, worldview and pro-sociality.

\section{Connecting our results to previous research}

Our finding that worldview affiliation was associated with increased pro-sociality largely because of greater pro-social opportunities is consistent with (and supportive of) other work on social networking influences within religious groups 2 42 44. However, our use of agent-based modeling and simulation enabled us to explore these relationships in a more dynamic way. For example, the results of our simulation showed that group affiliation was associated with lower trust and the removal of outgroup agents from online and offline social networks, with the latter being due to negative interactions within such networks. Identifying this pattern provides additional insight into the paradoxical co-occurrence of religious affiliation with greater pro-sociality (in the form of volunteering) via enhanced group social networking, on the one hand, and reduced trust of those with a different (majority/minority) identification, on the other 34,48 51.

Furthermore, our modeling helps to explain the homophily characteristic of supernatural worldview clubs (such as churches). Such social networks tend to be homogeneous and have less exposure to outgroup members, which increases the likelihood that ingroup members will interact with others who have high outgroup suspicion. This suggests that religious affiliation may constitute a double-edged sword when it comes to pro-sociality $45,52,56$.

We also found that active pro-sociality (i.e. volunteering) is enhanced among the affiliated, and that the higher levels of pro-sociality among affiliated supernatural believers stands in contrast to unaffiliated supernatural believers. This confirms other findings in the literature that indicate religious affiliation is more relevant than religious belief for predicting pro-sociality $34,45,57,60$. This also has implications for the use of group designations in the literature that combine believers and nonbelievers. Studies using designations such as unaffiliated or nones lump the least pro-social religiously-believing individuals together with nonbelieving and secular individuals, lending the impression that believing has prosocial advantages over nonbelieving. On the contrary, our modeling indicates that unaffiliated believers actually have lower pro-sociality than unaffiliated nonbelievers, largely attributable to the former's impoverished social networks. 
Our modeling has also provided insights into the causes of changes in religious belief and affiliation. Simulation experiments showed that greater tolerance of others at an earlier point in time predicted later reductions (but not increases) in supernatural belief. This was due to the way in which affiliated supernatural believers (unlike unaffiliated believers) were insulated from worldview conflicts. This means that those who transition from belief to nonbelief are typically unaffiliated individuals who also have lower outgroup suspicion and more heterogeneous networks that lead to belief-eroding encounters. This dynamic process appears consistent with the polarization hypothesis, which claims that pre-existing differences between believers and nonbelievers accelerate or snowball over time [61], increasing those differences through belief-reinforcing or belief-eroding experiences (respectively).

\section{Conclusion}

While there have been numerous studies on the relationship between religion and pro-sociality, we are unaware of any previous work connecting the worldview of individuals, their affiliation with worldview clubs, and their active and passive pro-sociality through data analysis and agent-based simulation. The work presented in this paper fills this gap. Our work operationalizes the following factors in both the WVS data and in an established agent based model: (1) natural and supernatural worldviews, (2) membership in supernatural worldview clubs, (3) active pro-sociality and (4) passive pro-sociality. We show that several statistically significant results emerge in both the data from the WVS and data collected from the agent-based simulation.

Specifically, we found that: (1) individuals affiliated with supernatural worldview clubs are actively pro-social at a higher rate than unaffiliated individuals, (2) individuals with a supernatural worldview are actively pro-social at a higher rate than individuals with a naturalist worldview, (3) but when considering pro-social actions not taken on behalf of a supernatural worldview club (i.e. tribal altruism), individuals with a naturalist worldview are actively pro-social at the same rate as individuals with a supernatural worldview, and (4) individuals with a naturalist worldview are passively pro-social (i.e. express tolerance and trust) at a higher rate than individuals with a supernatural worldview, especially when compared to individuals affiliated with a supernatural worldview club.

We also found that individuals who ultimately change their worldview or affiliation status with a supernatural worldview club exhibit distinctive passive pro-sociality profiles prior to their change. Individuals who move from a supernatural worldview to a natural worldview exhibit tolerance of others at a higher rate prior to their worldview change than individuals who move from a naturalist worldview to a supernatural worldview. In addition, individuals with a supernatural worldview who move from being affiliated to being unaffiliated with a supernatural worldview club exhibit trust of others at a higher rate than individuals with a supernatural worldview who move from being unaffiliated to being affiliated with a supernatural worldview club.

In each of these cases the agent-based modeling provided an explanation for why these results emerge. Simulation experiments showed that affiliation provides individuals with an additional social network that generates more pro-social action opportunities of all types. However, this network is likely to include agents with high outgroup suspicion, and the interactions an agent has within the network are more likely to increase the agent's outgroup suspicion, which leads them to trust fewer agents. Furthermore, even after an agent chooses to become unaffiliated it takes almost a year before the agent significantly reduces its outgroup suspicion value. This helps to explain why in the WVS data analysis it is an individual's affiliation status, rather than worldview, that largely determines their active and passive pro-sociality profile. This may not be the only explanation for these phenomena, but we have provided a formal and explicit description of one set of dynamics that do reproduce the results observed in the WVS data.

\section{References}

1. Einolf CJ. The link between religion and helping others: The role of values, ideas, and language. Sociology of Religion. 2011;72(4):435-455.

2. Lewis VA, MacGregor CA, Putnam RD. Religion, networks, and neighborliness: The impact of religious social networks on civic engagement. Social Science Research. 2013;42(2):331-346.

3. Pazhoohi F, Pinho M, Arantes J. Effect of Religious Day on Prosocial Behavior: A Field Study. International Journal for the Psychology of Religion. 2017;27(2):116-123. 
4. Stavrova O, Siegers P. Religious Prosociality and Morality Across Cultures: How Social Enforcement of Religion Shapes the Effects of Personal Religiosity on Prosocial and Moral Attitudes and Behaviors. Personality and Social Psychology Bulletin. 2014;40(3):315-333.

5. Stankov L, Lee J. Nastiness, Morality and Religiosity in 33 nations. Personality and Individual Differences. $2016 ; 99: 56-66$.

6. Atran S. In gods we trust: The evolutionary landscape of religion. Oxford University Press; 2004.

7. Norenzayan A. Big gods: How religion transformed cooperation and conflict. Princeton University Press; 2013.

8. Wildman WJ. Science and religious anthropology: A spiritually evocative naturalist interpretation of human life. Routledge; 2016.

9. Shults FL. Practicing safe sects: Religious reproduction in scientific and philosophical perspective. Brill; 2018.

10. Shults FL, Wildman WJ, Diallo S, Puga-Gonzalez I, Voas D. The Virtual Society Analytics Platform. In: Proceedings of The Social Simulation Conference. European Social Simulation Association; 2018.

11. Gore RJ, Lynch CJ, Kavak H. Applying statistical debugging for enhanced trace validation of agent-based models. Simulation. 2017;93(4):273-284.

12. Epstein JM, Axtell R. Growing artificial societies: social science from the bottom up. Brookings Institution Press; 1996.

13. Association WVS, et al. World values survey Waves 1-6: Aggregate. Aggregate File Producer: Asep/JDS, Madrid Spain. 2018;

14. Association WVS, et al. World values survey: Longitudinal. Aggregate File Producer: Asep/JDS, Madrid Spain. 2018 ;

15. Saroglou V. Religion's role in prosocial behavior: Myth or reality? Psychology of Religion Newsletter: American Psychological Association Division 36. 2006;31:1-8.

16. Lam PY. As the flocks gather: How religion affects voluntary association participation. Journal for the scientific study of religion. 2002;41(3):405-422.

17. Preston JL, Ritter RS, Hernandez JI. Principles of Religious Prosociality: A Review and Reformulation. Social and Personality Psychology Compass. 2010;4(8):574-590.

18. Forbes KF, Zampelli EM. The impacts of religion, political ideology, and social capital on religious and secular giving: evidence from the 2006 Social Capital Community Survey. Applied Economics. 2013;45(17):2481-2490.

19. Park JZ, Smith C. 'To Whom Much Has Been Given...' Religious Capital and Community Voluntarism Among Churchgoing Protestants. Journal for the Scientific Study of Religion. 2000;39(3):272-286.

20. Henrich J, Ensminger J, McElreath R, Barr A, Barrett C, Bolyanatz A, et al. Markets, religion, community size, and the evolution of fairness and punishment. science. 2010;327(5972):1480-1484.

21. Saroglou V, Delpierre V, Dernelle R. Values and religiosity: A meta-analysis of studies using Schwartz's model. Personality and Individual Differences. 2004;37(4):721-734.

22. Borgonovi F. Divided we stand, united we fall: Religious pluralism, giving, and volunteering. American Sociological Review. 2008;73(1):105-128.

23. Cragun RT. What You Don't Know about Religion (but Should). Pitchstone Publishing (US\&CA); 2014.

24. Storm I. Civic Engagement in Britain: The Role of Religion and Inclusive Values. European Sociological Review. 2015;31(1):14-29. 
25. Martin LH, Wiebe D. Pro- and Assortative-Sociality in the Formation and Maintenance of Religious Groups. The Journal of Cognitive Science. 2014;2(1):129-142.

26. Preston JL, Ritter RS. Different Effects of Religion and God on Prosociality With the Ingroup and Outgroup. Personality and Social Psychology Bulletin. 2013;39(11):1471-1483.

27. Ginges J, Sheikh H, Atran S, Argo N. Thinking from God's perspective decreases biased valuation of the life of a nonbeliever. Proceedings of the National Academy of Sciences of the United States of America. 2016;113(2):316-319.

28. Blogowska J, Lambert C, Saroglou V. Religious Prosociality and Aggression: It's Real. Journal for the Scientific Study of Religion. 2013;52(3):524-536.

29. Zuckerman P. Living the Secular Life: New Answers to Old Questions; 2014.

30. Decety J, Cowell JM, Lee K, Mahasneh R, Malcolm-Smith S, Selcuk B, et al. The Negative Association between Religiousness and Children's Altruism across the World. Current Biology. 2015;25(22):2951-2955.

31. Uslaner EM. Volunteering and social capital: How trust and religion shape civic participation in the United States; 2001. p. 104-117.

32. Choi NG, DiNitto DM. Predictors of time volunteering, religious giving, and secular giving: Implications for nonprofit organizations. J Soc \& Soc Welfare. 2012;39:93.

33. Hempel LM, Matthews T, Bartkowski J. Trust in a "fallen world": The case of Protestant theological conservatism. Journal for the Scientific Study of Religion. 2012;51(3):522-541.

34. Galen LW, Sharp M, McNulty A. Nonreligious group factors versus religious belief in the prediction of prosociality. Social Indicators Research. 2015;122(2):411-432.

35. Kloet J, Galen LW. Personality and social integration factors distinguishing nonreligious from religious groups: The importance of controlling for attendance and demographics. Archive for the Psychology of Religion. 2011;33(2):205-228.

36. Tajfel H, Turner J. An integrative theory of intergroup conflict. The Social Psychology of Intergroup Relations. 1979 ;.

37. Tajfel H. Social identity and intergroup relations. Contemporary Sociology. 1985;14(4):520.

38. Swann WB, Gomez A, Huici C, Morales JF, Hixon JG. Identity Fusion and Self-Sacrifice: Arousal as a Catalyst of Pro-Group Fighting, Dying, and Helping Behavior. Journal of Personality and Social Psychology. 2010;99(5):824-841.

39. Sheikh H, Atran S, Ginges J, Wilson L, Obeid N, Davis R. The Devoted Actor as Parochial Altruist: Sectarian Morality, Identity Fusion, and Support for Costly Sacrifices. Cliodynamics: The Journal of Quantitative History and Cultural Evolution. 2014;5(1).

40. McGregor HA, Lieberman JD, Greenberg J, Solomon S, Arndt J, Simon L, et al. Terror management and aggression: evidence that mortality salience motivates aggression against worldview-threatening others. Journal of Personality and Social Psychology. 1998;74(3):590-605.

41. Vail KE, Rothschild ZK, Weise DR, Solomon S, Pyszczynski T, Greenberg JL. A Terror Management Analysis of the Psychological Functions of Religion. Personality and Social Psychology Review. 2010;14(1):84-94.

42. Beyerlein K, Hipp JR. From pews to participation: The effect of congregation activity and context on bridging civic engagement. Social Problems. 2006;53(1):97-117.

43. Jackson EF, Bachmeier MD, Wood JR, Craft EA. Volunteering and charitable giving: Do religious and associational ties promote helping behavior? Nonprofit and Voluntary Sector Quarterly. 1995;24(1):59-78. 
44. Lim C, Putnam RD. Religion, social networks, and life satisfaction. American sociological review. 2010;75(6):914-933.

45. Putnam RD, Campbell DE, Garrett SR. American Grace: How Religion Divides and Unites Us; 2010.

46. Merino SM. Religious social networks and volunteering: Examining recruitment via close ties. Review of Religious Research. 2013;55(3):509-527.

47. Bekkers R, Schuyt T. And who is your neighbor? Explaining denominational differences in charitable giving and volunteering in the Netherlands. Review of Religious Research. 2008; p. 74-96.

48. Cheadle JE, Schwadel P. The 'friendship dynamics of religion,'or the 'religious dynamics of friendship'? A social network analysis of adolescents who attend small schools. Social Science Research. 2012;41(5):1198-1212.

49. Fitzgerald CJ, Wickwire JH. Religion and political affiliation's influence on trust and reciprocity among strangers. Journal of Social, Evolutionary, and Cultural Psychology. 2012;6(2):158.

50. Welch MR, Sikkink D, Loveland MT. The Radius of Trust: Religion, Social Embeddedness and Trust in Strangers. Social Forces. 2007;86(1):23-46.

51. Loveland MT, Capella AG, Maisonet I. Prosocial skeptics: Skepticism and generalized trust. Critical Research on Religion. 2017;5(3):251-265.

52. Rhodes J. The Ties That Divide: Bonding Social Capital, Religious Friendship Networks, and Political Tolerance among Evangelicals*. Sociological Inquiry. 2012;82(2):163-186.

53. Goplen J, Plant EA. A Religious Worldview: Protecting One's Meaning System Through Religious Prejudice. Personality and Social Psychology Bulletin. 2015;41(11):1474-1487.

54. Ramsay JE, Pang JS, Shen MJ, Rowatt WC. Rethinking Value Violation: Priming Religion Increases Prejudice in Singaporean Christians and Buddhists. International Journal for the Psychology of Religion. 2014;24(1):1-15.

55. Kossowska M, Sekerdej M. Searching for certainty: Religious beliefs and intolerance toward value-violating groups. Personality and Individual Differences. 2015;83:72-76.

56. Saribay SA, Yilmaz O. Analytic cognitive style and cognitive ability differentially predict religiosity and social conservatism. Personality and Individual Differences. 2017;114:24-29.

57. Brooks AC. Who really cares: The surprising truth about compassionate conservatism-america's charity divide-who gives, who doesn't, and why it matters. Basic Books (AZ); 2007.

58. Monsma SV. Religion and philanthropic giving and volunteering: Building blocks for civic responsibility. Interdisciplinary Journal of Research on Religion. 2007;3.

59. Becker PE, Dhingra PH. Religious involvement and volunteering: Implications for civil society. Sociology of Religion. 2001;62(3):315-335.

60. Galen LW. Does religious belief promote prosociality? A critical examination. Psychological bulletin. 2012;138(5):876.

61. Ozorak EW. Social and cognitive influences on the development of religious beliefs and commitment in adolescence. Journal for the scientific study of religion. 1989; p. 448-463. 